Article

\title{
Neuroprotective Effects of Growth Hormone (GH) and Insulin-Like Growth Factor Type 1 (IGF-1) after Hypoxic-Ischemic Injury in Chicken Cerebellar Cell Cultures
}

\author{
Rosario Baltazar-Lara ${ }^{1}$, José Ávila-Mendoza ${ }^{1,2}$, Carlos G. Martínez-Moreno ${ }^{1}$, Martha Carranza ${ }^{1}$, \\ Santiago Pech-Pool ${ }^{1}$, Olivia Vázquez-Martínez ${ }^{1}$, Mauricio Díaz-Munoz ${ }^{1}{ }^{1}$, Maricela Luna ${ }^{1, *}{ }^{1}$ and \\ Carlos Arámburo ${ }^{1, *(1)}$
}

1 Departamento de Neurobiología Celular y Molecular, Instituto de Neurobiología, Campus Juriquilla, Universidad Nacional Autónoma de México, Querétaro 76230, Mexico; maba192@comunidad.unam.mx (R.B.-L.); javila@comunidad.unam.mx (J.Á.-M.); cgmartin@comunidad.unam.mx (C.G.M.-M.); macasa@unam.mx (M.C.); agronomiapech@hotmail.com (S.P.-P.); ovazquez@comunidad.unam.mx (O.V.-M.); mdiaz@comunidad.unam.mx (M.D.-M.)

2 Department of Molecular, Cellular and Developmental Biology, The University of Michigan, Ann Arbor, MI 48109, USA

* Correspondence: lunam@unam.mx (M.L.); aramburo@unam.mx (C.A.); Tel.: +52-55-5623-4066 (M.L.); +52-55-5623-4065 (C.A.); Fax: +52-55-5623-4005 (M.L. \& C.A.)

check for updates

Citation: Baltazar-Lara, R.; Ávila-Mendoza, J.; Martínez-Moreno, C.G.; Carranza, M.; Pech-Pool, S.; Vázquez-Martínez, O.; Díaz-Muñoz, M.; Luna, M.; Arámburo, C. Neuroprotective Effects of Growth Hormone (GH) and Insulin-Like Growth Factor Type 1 (IGF-1) after Hypoxic-Ischemic Injury in Chicken Cerebellar Cell Cultures. Int. J. Mol. Sci. 2021, 22, 256. https://doi.org/ $10.3390 /$ ijms $/ 22010256$

Received: 30 November 2020 Accepted: 22 December 2020 Published: 29 December 2020

Publisher's Note: MDPI stays neutral with regard to jurisdictional clai$\mathrm{ms}$ in published maps and institutional affiliations.

Copyright: (C) 2020 by the authors. Licensee MDPI, Basel, Switzerland. This article is an open access article distributed under the terms and conditions of the Creative Commons Attribution (CC BY) license (https:// creativecommons.org/licenses/by/ $4.0 /)$.
Abstract: It has been reported that growth hormone (GH) and insulin-like growth factor 1 (IGF-1) exert protective and regenerative actions in response to neural damage. It is also known that these peptides are expressed locally in nervous tissues. When the central nervous system (CNS) is exposed to hypoxia-ischemia (HI), both GH and IGF-1 are upregulated in several brain areas. In this study, we explored the neuroprotective effects of GH and IGF-1 administration as well as the involvement of these endogenously expressed hormones in embryonic chicken cerebellar cell cultures exposed to an acute $\mathrm{HI}$ injury. To induce neural damage, primary cultures were first incubated under hypoxic-ischemic $\left(<5 \% \mathrm{O}_{2}, 1 \mathrm{~g} / \mathrm{L}\right.$ glucose) conditions for $12 \mathrm{~h}(\mathrm{HI})$, and then incubated under normal oxygenation and glucose conditions ( $\mathrm{HI}+\mathrm{Ox}$ ) for another $24 \mathrm{~h}$. GH and IGF-1 were added either during or after $\mathrm{HI}$, and their effect upon cell viability, apoptosis, or necrosis was evaluated. In comparison with normal controls ( $\mathrm{Nx}, 100 \%)$, a significant decrease of cell viability $(54.1 \pm 2.1 \%)$ and substantial increases in caspase- 3 activity (178.6 $\pm 8.7 \%)$ and LDH release $(538.7 \pm 87.8 \%)$ were observed in the HI + Ox group. On the other hand, both GH and IGF-1 treatments after injury ( $\mathrm{HI}+\mathrm{Ox}$ ) significantly increased cell viability $(77.2 \pm 4.3 \%$ and $72.3 \pm 3.9 \%$, respectively) and decreased both caspase- 3 activity (118.2 $\pm 3.8 \%$ and $127.5 \pm 6.6 \%$, respectively) and LDH release $(180.3 \pm 21.8 \%$ and $261.6 \pm 33.9 \%$, respectively). Incubation under $\mathrm{HI}+\mathrm{Ox}$ conditions provoked an important increase in the local expression of GH (3.2-fold) and IGF-1 (2.5-fold) mRNAs. However, GH gene silencing with a specific small-interfering RNAs (siRNAs) decreased both GH and IGF-1 mRNA expression (1.7-fold and 0.9-fold, respectively) in the HI + Ox group, indicating that GH regulates IGF1 expression under these incubation conditions. In addition, GH knockdown significantly reduced cell viability $(35.9 \pm 2.1 \%)$ and substantially increased necrosis, as determined by LDH release $(1011 \pm 276.6 \%)$. In contrast, treatments with GH and IGF-1 stimulated a partial recovery of cell viability $(45.2 \pm 3.7 \%$ and $53.7 \pm 3.2 \%)$ and significantly diminished the release of LDH $(320.1 \pm 25.4 \%$ and $421.7 \pm 62.2 \%$ ), respectively. Our results show that GH, either exogenously administered and/or locally expressed, can act as a neuroprotective factor in response to hypoxic-ischemic injury, and that this effect may be mediated, at least partially, through IGF-1 expression.

Keywords: hypoxia-ischemia; growth hormone; IGF-1; cerebellum; neuroprotection 


\section{Introduction}

It is clearly established that the growth hormone (GH)/insulin-like growth factor-1 (IGF-1) axis is involved in the regulation of somatic growth and several metabolic processes in vertebrates. It is also known that these growth factors participate in the control of neurogenesis, gliogenesis, myelinization, and brain plasticity, as well as in the proliferation of neural precursors [1-3] during the development of the central nervous system (CNS), and that they are implicated in the modulation of diverse neural and brain functions, such as cognition, learning, memory, neuroprotection, and regeneration, among others [4-6].

Many reports have shown that both GH and IGF-1 are also expressed in several brain areas (e.g., hypothalamus, hippocampus, cortex, and cerebellum) [7-9], so it is possible that the effect of these factors upon some CNS functions may be the result of a complex interaction between endocrine, paracrine, and autocrine mechanisms. Several studies have described that both circulating and locally expressed GH and IGF-1 are involved in neuroprotective actions in response to neural injury [4,10-19]. Furthermore, it was reported that GH and IGF-1 provoked an increase in the number of progenitor cells, neurons, oligodendrocytes, and astrocytes in the brain, as well as in angiogenesis, thus augmenting the cerebral blood supply $[2,20]$. It was also suggested that at least part of the observed neuroprotective effects can be the result of a rise in the local GH and IGF-1 expression, which occurs in damaged tissues following brain injury. Previous studies reported that exogenous GH administration increased the cell viability of cultured cerebellar neurons exposed to hypoxic conditions, and that it prevented apoptosis by triggering the PI3K/Akt pathway, inhibiting caspase-3 activity, and inducing Bcl-2 expression [11]. Likewise, the participation of GH and IGF-1 in the neuroprotective mechanisms that occur after neural harm has been described in the CNS of rats, both in vivo and in vitro [14,20]; this was also reported in chicken neuroretina, where endogenously expressed GH exerted antiapoptotic actions and promoted the survival of retinal ganglion cells (RGCs) [21-23]. Similarly, the neuroprotective actions of IGF-1 in response to a hypoxia-ischemia (HI) injury, both in vivo and in vitro, involve the activation of PI3K/Akt and MAP/ERK pathways, the inactivation of glycogen synthase kinase 3 beta (GSK3ß), and a concomitant reduction in caspase- 3 and caspase-9 activities [24-26]. In addition to its protective actions, GH was also implicated in the regenerative response of neurons [20], as seen by the induction of neural outgrowths in primary neuroretinal cell cultures after a kainate-induced excitotoxic injury [17].

The upregulation of endogenous GH and IGF-1 expression observed in response to an $\mathrm{HI}$ neural injury has been suggested as part of the neuroprotective mechanism [27,28]. Accordingly, when either organotypic or primary cerebellar cell cultures were exposed to $\mathrm{HI}$ conditions, a significant increase in local GH expression was reported [11], and in vivo studies showed that a reduction of damage after brain $\mathrm{HI}$ injury correlated with an increase in the local expression of IGF-1 [29]. This upregulation has been causally linked to events occurring during the subacute phase of $\mathrm{HI}$ injury $[28,30]$.

Whether GH neuroprotective actions are exerted directly or mediated by IGF-1 still remains controversial [31]. Moreover, the contribution of circulating versus locally expressed GH or IGF-1 and their role in neuroprotection in response to a neural harm deserve further research. To this end, in this work we study the effects on cell viability, signaling pathways, apoptosis, and necrosis when treating primary cerebellar cell cultures exposed to acute $\mathrm{HI}$ injury and reoxygenation (HI + Ox) with either exogenously added GH and IGF-1, or by knocking-down the endogenous expression of GH and IGF-1 genes using specific small-interfering RNAs (siRNAs), to determine their influence on the neuroprotective response to neural damage.

\section{Results}

Figure 1 depicts the experimental design and time frame employed to study the neuroprotective effects of GH and IGF-1 in cerebellar cell cultures exposed to hypoxiaischemia (HI) for $12 \mathrm{~h}$ and followed by reoxygenation conditions (HI + Ox) for another $24 \mathrm{~h}$. 


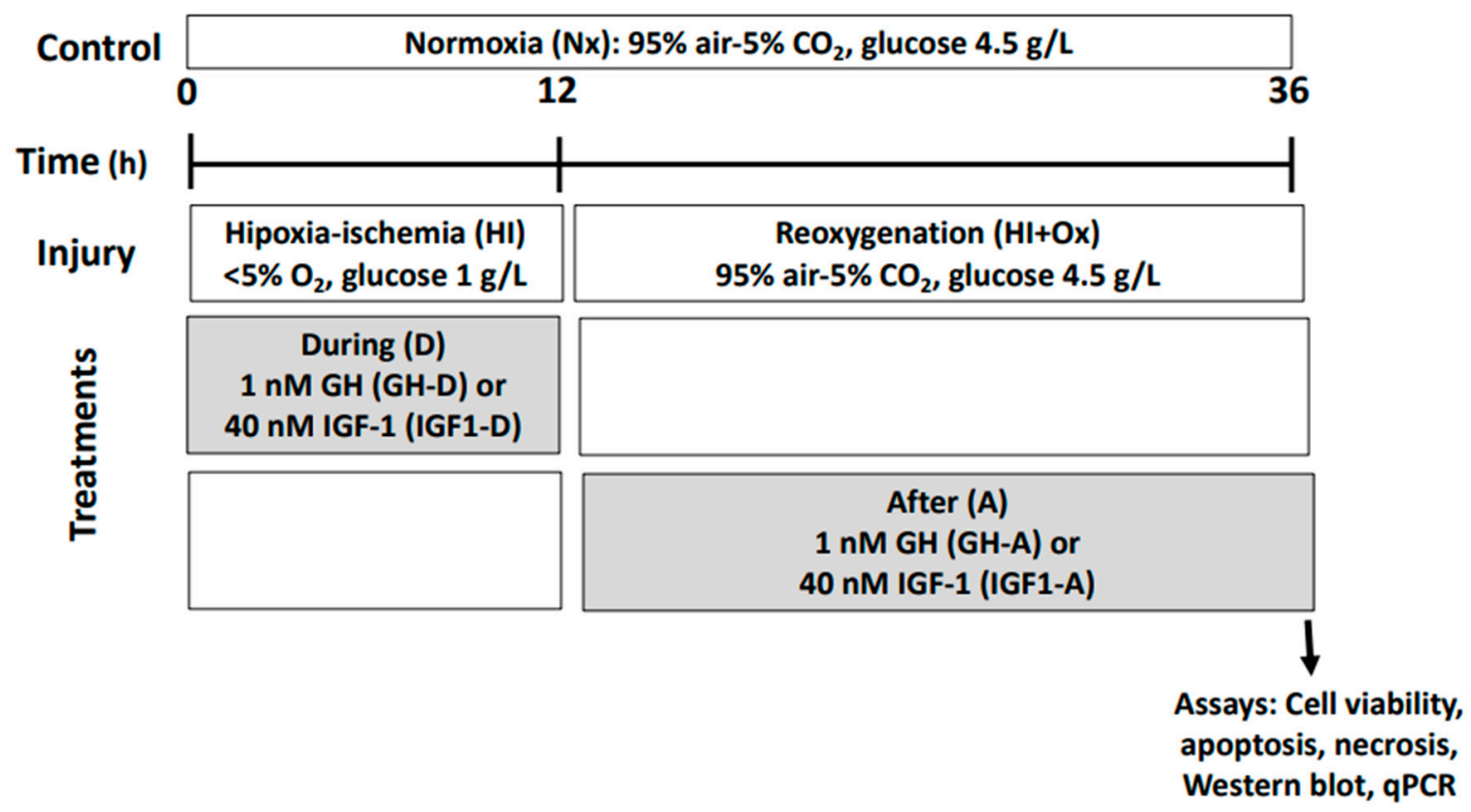

Figure 1. Schematic representation of the experimental design. Primary cerebellar cell cultures were first incubated under hypoxic-ischemic ( $\mathrm{HI} ;<5 \% \mathrm{O}_{2}$, glucose $1 \mathrm{~g} / \mathrm{L}$ ) conditions for $12 \mathrm{~h}$, and then incubated under normal oxygenation and glucose conditions for another $24 \mathrm{~h}$ (reoxygenation, $\mathrm{HI}+\mathrm{Ox}$ ). Growth hormone $(\mathrm{GH})$ and insulin-like growth factor 1 (IGF-1) treatments were added either during $\mathrm{HI}$ conditions or after in $\mathrm{HI}+\mathrm{Ox}$ (D denotes during, A denotes after); their effect on cell viability (MTT assay), apoptosis (Caspase-3 activity assay), necrosis (LDH activity), immunoreactivity of several markers (i.e., NeuN, DCX, pAkt, pERK1/2, Bcl-2 by Western blot), and expression of GH, GHR, IGF-1 and IGF-1R mRNAs by qPCR was evaluated.

\subsection{Hypoxic-Ischemic Conditions Increase HIF-1 $\alpha$ Expression in Primary Cerebellar Cell Cultures}

As it is shown in Figure 2, immunocytochemical confocal analysis revealed that relevant morphological changes occurred when cerebellar cell cultures were exposed to hypoxic-ischemic conditions ( $\mathrm{HI},<5 \% \mathrm{O}_{2} ; 1 \mathrm{~g} / \mathrm{L}$ glucose) in comparison with normoxic conditions ( $\mathrm{Nx}, 95 \%$ air- $5 \% \mathrm{CO}_{2} ; 4.5 \% \mathrm{~g} / \mathrm{L}$ glucose). These changes are as follows: (1) The number of cells (estimated by DAPI staining, blue) clearly decreased (Figure 2Bd vs. Figure 2Ba); (2) a significant increase in cell clumping indicating a rise in cell lysis (white arrowheads Figure 2Ae,f vs. Figure 2Ab,c) was observed; (3) modification of B-tubulin III organization within neural cells (Figure 2Af vs. Figure 2Ac) was evident; and (4) the immunoreactivity (IR) to hypoxia-inducible factor 1-alpha (HIF-1 $\alpha$ ) significantly increased (3-fold, $p<0.0001$, Figure 2C) in the HI-exposed cultures (Figure 2Ae,Be,Bf). The HIF$1 \alpha$-IR was abundantly present in the cytoplasm (Figure $2 \mathrm{Be}, \mathrm{f}$ ) and the perinuclear areas (Figure 2Bf, white arrows) of the cells exposed to $\mathrm{HI}$ for $12 \mathrm{~h}$ in comparison with $\mathrm{Nx}$ (Figure 2Bb,c).

2.2. Effects of Hypoxic-Ischemic (Acute Injury) and Reoxygenation (Subacute Injury) Incubation Conditions on Cell Viability, Apoptosis, and Necrosis in Primary Cerebellar Cultures

Supplementary Figure S1A shows that the viability of cerebellar cell cultures significantly decreased $(24.1 \pm 6.3 \%, p<0.001)$ when exposed to $\mathrm{HI}$ conditions for $12 \mathrm{~h}$ in comparison to the Nx controls $(100 \pm 2.7 \%)$. When the cultures were returned to reoxygenation conditions (after HI) in a Neurobasal B-27 medium (HI + Ox) for another $24 \mathrm{~h}$, the cell viability was further diminished $(50.3 \pm 4.2 \%)$, both in comparison to $\mathrm{Nx}(p<0.0001)$ and to $\mathrm{HI}(p<0.01)$ groups. Accordingly, incubation under both $\mathrm{HI}$ and $\mathrm{HI}+\mathrm{Ox}$ conditions significantly increased the apoptosis in cerebellar cultures, as determined by caspase-3 activity $(203.9 \pm 12.9 \%, p<0.0001$, and $173.8 \pm 13.4 \%, p<0.001$, respectively) in comparison to Nx controls (100 $\pm 7.1 \%$ ) (Supplementary Figure S1B). Moreover, a drastic elevation 
in cell necrosis, as revealed by LDH release, was observed mainly under $\mathrm{HI}+\mathrm{Ox}$ conditions $(538.7 \pm 87.8 \%, p<0.0001)$ in comparison to $\mathrm{Nx}(100 \pm 4.5 \%)$ and $\mathrm{HI}(152.4 \% \pm 8.2$, $p<0.006$ ) (Supplementary Figure S1C).

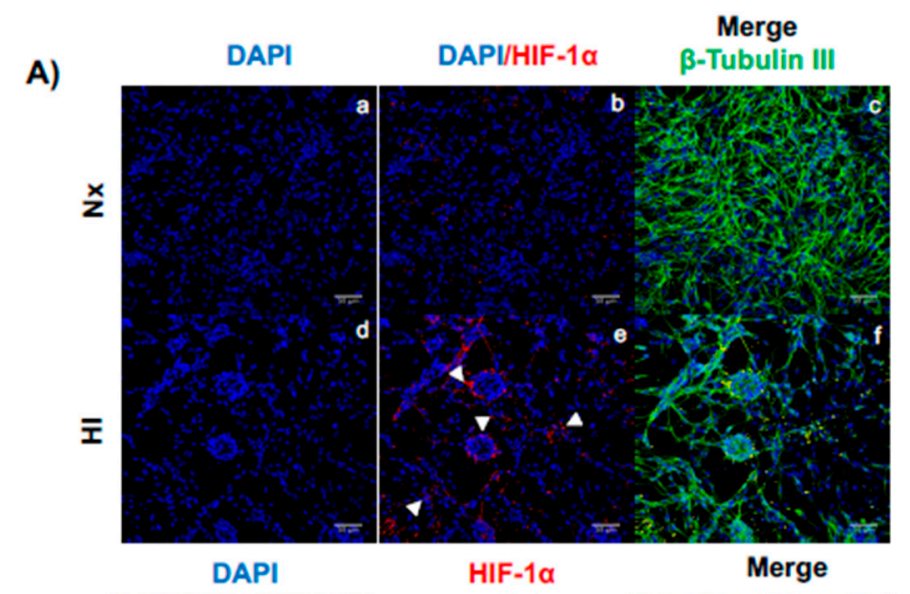

B)
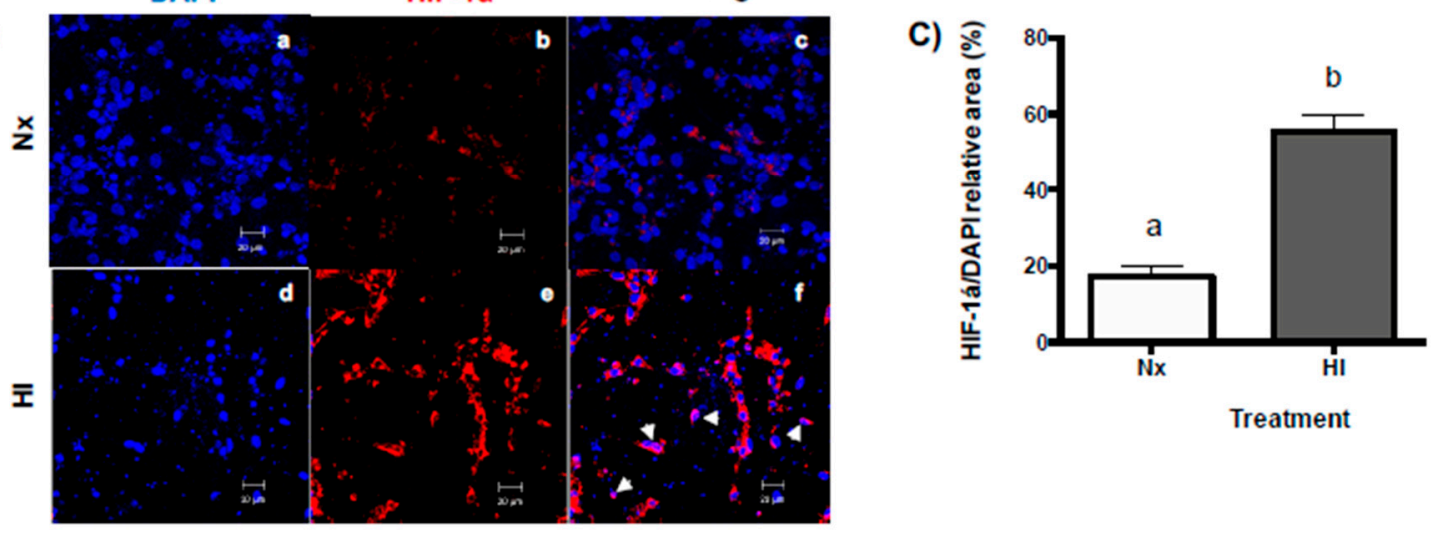

Figure 2. Expression of hypoxia-inducible factor-1 alpha (HIF-1 $\alpha$ ) and cell organization in primary cerebellar cultures exposed to either normoxic ( $\mathrm{Nx}, 95 \%$ air- $5 \% \mathrm{CO}_{2}, 4.5 \mathrm{~g} / \mathrm{L}$ glucose) or hypoxic-ischemic ( $\mathrm{HI},<5 \% \mathrm{O}_{2}, 1 \mathrm{~g} / \mathrm{L}$ glucose) incubation conditions for $12 \mathrm{~h}$. (A) Representative ICC confocal images show the expression of HIF-1 $\alpha$ (red), the neuronal marker ß-Tubulin III (green), and cell nuclei counterstained with DAPI (blue), under Nx (Aa-Ac) and HI (Ad-Af) conditions. HIF- $1 \alpha$ immunoreactivity was enhanced after $\mathrm{HI}$ exposure (white arrows, Ae) in comparison to $\mathrm{Nx}$ (Ab). In addition, in contrast to regular cell distribution in the $\mathrm{Nx}$ controls, an important proportion of cell clumping and reorganization of $B$-Tubulin III was observed in HI-injured cultures. Scale bars $=50 \mu \mathrm{m}$. (B) Representative ICC confocal images show the effect of HI upon the cell nuclei number (DAPI, blue) and HIF-1 $\alpha$ (red) expression under Nx (Ba-Bc) and HI (Bd-Bf) incubation conditions. Merged images show that hypoxia-ischemia injury provoked an important reduction in cell number as well as a significant enhancement of HIF- $1 \alpha$ immunoreactivity, mainly in the perinuclear areas (white arrows, Bf) in comparison to the Nx controls (2Bc). Scale bars $=20 \mu \mathrm{m}$. (C) Quantification of data in (B) is presented as the percentage (\%) of the ratio between HIF- $1 \alpha$ and DAPI fluorescence. Each bar represents the mean \pm SEM, $n=4$ independent experiments performed in duplicate. Different letters indicate significant difference $(p<0.0001)$ as determined by an unpaired Student's $t$ test.

2.3. Treatments with GH and IGF-1 Protect Primary Cerebellar Cell Cultures from Damage When Administered during or after $\mathrm{HI}$ and $\mathrm{HI}+\mathrm{Ox}$ Incubation Conditions

The potential effects of GH and IGF-1 to protect cells from damage were studied when these hormones were administered either during (denoted by $\mathrm{D}$ ) the acute phase of hypoxia (HI, $12 \mathrm{~h}$ ) or after it (denoted by A) while they are in the subacute phase of injury in the reoxygenation incubation period ( $\mathrm{HI}+\mathrm{Ox}, 24 \mathrm{~h}$ ), as determined by analyzing their impact on cell viability (MTT assay), apoptosis (caspase-3 activity), and necrosis (LDH release) in primary cerebellar cell cultures. As it is shown in Figure 3A,B, cell viability 
decreased significantly under $\mathrm{HI}+$ Ox conditions $(54.1 \pm 2.1 \%)$ in comparison to $\mathrm{Nx}$ controls $(100 \pm 3.7 \%)$. Interestingly, treatment with $1 \mathrm{nM} \mathrm{rcGH}$ provoked a significant recovery of cell viability either when administered during the acute phase $(\mathrm{HI}+\mathrm{Ox} \mathrm{GH}-\mathrm{D}$, $84.4 \pm 5.4 \%, p<0.0001)$ or in the subacute phase (HI + Ox GH-A, $77.2 \pm 4.2 \%, p<0.0001)$ of injury. On the other hand, caspase- 3 activity clearly increased under $\mathrm{HI}+\mathrm{Ox}$ incubation conditions (178 $\pm 8.7 \%)$ compared to $\mathrm{Nx}(100 \pm 2.9 \%)$, while the addition of rcGH prevented apoptosis significantly $(118.2 \pm 3.8 \%, p<0.0001)$ only when applied in the reoxygenation period (HI + Ox GH-A, Figure 3C,D). Furthermore, necrosis was significantly augmented under $\mathrm{HI}+\mathrm{Ox}$ conditions $(538.7 \pm 87.8 \%, p<0.0001)$ in relation to $\mathrm{Nx}$, whereas treatment with $1 \mathrm{nM} \mathrm{rcGH}$ appreciably blocked this effect under both GH-D $(169.0 \pm 19.9 \%, p<0.01)$ and GH-A $(180.3 \pm 21.8 \%, p<0.0002)$ administration protocols (Figure 3E,F, respectively).

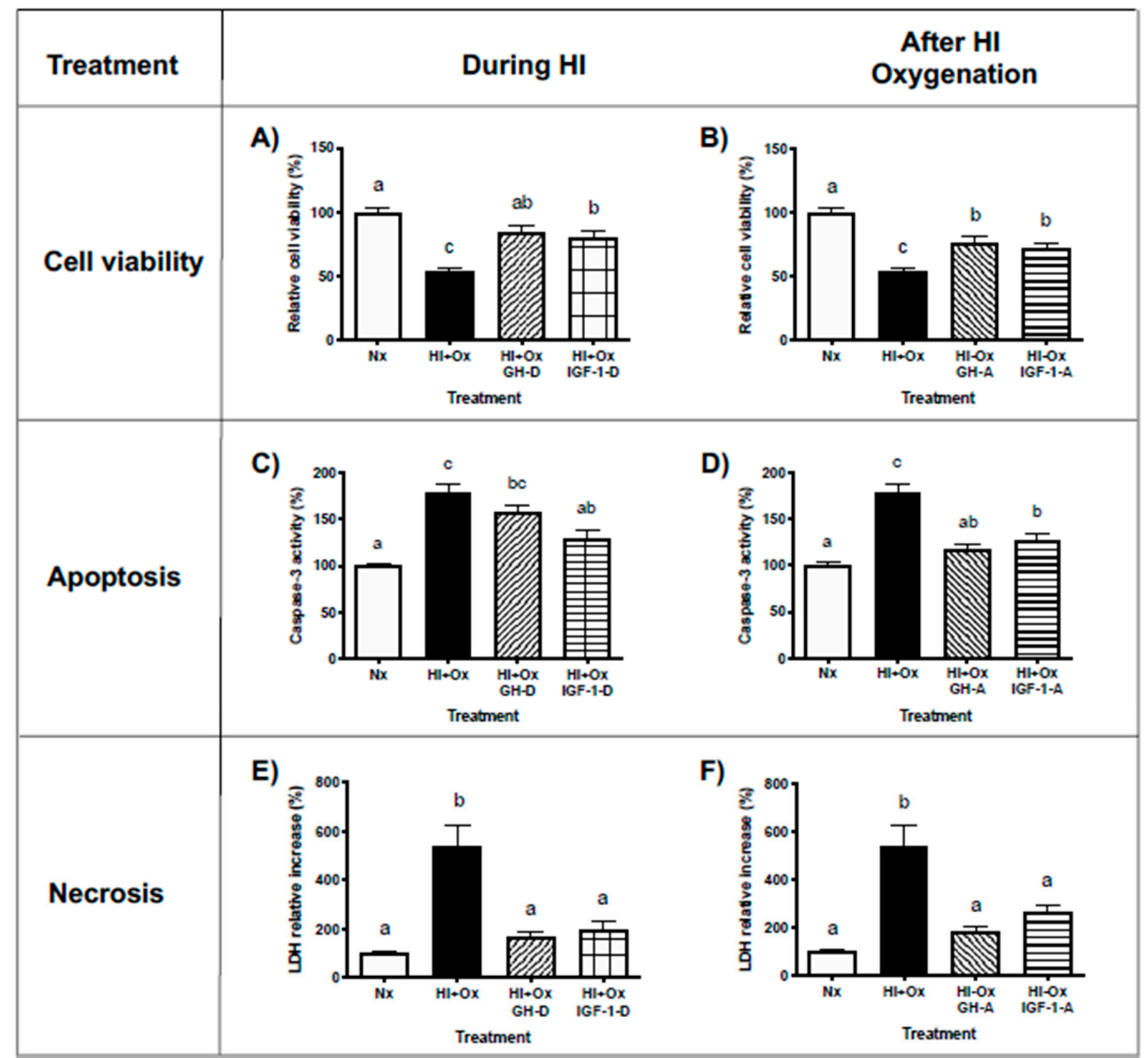

Figure 3. Effects of GH or IGF-1 treatments upon cell viability, apoptosis, and necrosis in primary cerebellar cultures exposed to Nx, HI, or HI + Ox incubation conditions. The hormones (1 nM GH or $40 \mathrm{nM}$ IGF-1) were administered either during (denoted by D) the acute $12 \mathrm{~h}$ injury phase (HI, panels $(\mathbf{A}, \mathbf{C}, \mathbf{E})$ ) or after it (denoted by $\mathrm{A}$ ); this occurred in the subacute phase in the reoxygenation $24 \mathrm{~h}$ period $(\mathrm{HI}+\mathrm{Ox}$, panels $(\mathbf{B}, \mathbf{D}, \mathbf{F}))$. Panels $(\mathbf{A}, \mathbf{B})$ show the analysis of cell viability as determined by the MTT assay. Panels (C,D) show the evaluation of apoptosis, measuring caspase-3 activity. Panels (E,F) show cell necrosis, as determined by LDH activity released to the culture media. Values are reported as percentage change in relation with the normoxic $(\mathrm{Nx})$ control groups (100\%). Both hormones were capable of recovering cell viability (panels $(\mathbf{A}, \mathbf{B}))$ and decreasing cell necrosis (panels $(\mathbf{E}, \mathbf{F})$ ) when administered either during the acute injury phase (HI + Ox GH-D; $\mathrm{HI}+\mathrm{Ox}$ IGF-1-D) or in the reoxygenation period (HI + Ox GH-A; HI + Ox IGF-1-A). On the other hand, IGF-1 treatment substantially reduced caspase-3 activity in both conditions (panels (C,D)), whereas GH treatment was only effective when added in the subacute injury phase (HI + Ox GH-A). Bars represent the mean $\pm \mathrm{SEM}, n=5$ independent experiments performed in triplicate. Groups with different letters are significantly different by one-way ANOVA and Tukey's post hoc test $(p<0.01)$. 
Likewise, treatment with $40 \mathrm{nM}$ rhIGF-1 promoted a significant recovery of cell viability when added either during acute (HI + Ox IGF-1-D, $79.6 \pm 5.9 \%, p<0.0004$, Figure 3A) or subacute (HI + Ox IGF-1-A, $72.3 \pm 3.9 \%, p<0.01$, Figure 3B) phases of injury, as compared to $\mathrm{HI}+\mathrm{Ox}$ conditions alone $(54.1 \pm 2.1 \%)$. Moreover, the addition of IGF-1 reduced the caspase-3 activity under both conditions, i.e., HI + Ox IGF-1-D $(130.2 \pm 8.7 \%, p<0.0005$, Figure 3C) and HI + Ox IGF-1-A $(127.5 \pm 6.6 \%, p<0.0001$, Figure 3D), respectively, in comparison with $\mathrm{HI}+\mathrm{Ox}(178.6 \pm 8.7 \%)$. Furthermore, the administration of IGF-1 also elicited a significant decrease in necrosis, as determined by LDH release into the culture media, when supplemented under either HI + Ox IGF-1-D $(193.6 \pm 40.1 \%, p<0.03$, Figure 3E) or HI + Ox IGF-1-A $(261.6 \pm 33.9 \%, p<0.01$, Figure 3F), as compared with $\mathrm{HI}+\mathrm{Ox}(538.7 \pm 87.9 \%)$ incubation conditions.

\subsection{Treatments with GH and IGF-1 Protect Mature Neurons and Neuronal Precursors after an} Acute Hypoxic-Ischemic Injury

The protective effects of GH and IGF-1 upon neuronal subpopulations in primary cerebellar cell cultures exposed to hypoxic-ischemic conditions were analyzed by determining the expression of NeuN (mature neurons) and DCX (neuronal precursors) markers. As it is shown in Figure 4A,B, exposure of cultures to $\mathrm{HI}+$ Ox conditions resulted in a significant decrease $(52.5 \pm 8.7 \%, p<0.01)$ in NeuN immunoreactive (IR) bands in relation to the Nx control $(100 \pm 9.1 \%)$, as analyzed by Western blot. However, the addition of either $1 \mathrm{nM}$ rcGH or $40 \mathrm{nM}$ rhIGF-1 at the reoxygenation period, after the acute injury event, significantly blocked such effect $(\mathrm{HI}+\mathrm{Ox} \mathrm{GH}-\mathrm{A}, 126 \pm 11.5 \%, p<0.0004$; $\mathrm{HI}+\mathrm{Ox}$ IGF-1-A, $111.6 \pm 15.1 \%, p<0.01$, respectively) and restored the expression of NeuN levels (Figure 4B). On the other hand, Figure 4C,D shows that $\mathrm{HI}+$ Ox conditions did not modify the expression of DCX-IR band $(93.3 \pm 6.3 \%)$ in comparison to the $\mathrm{Nx}$ control (100 $\pm 0.25 \%)$. However, the administration of rcGH or rhIGF-1 after injury resulted in a significant increase for DCX-IR (HI + Ox GH-A: $125.4 \pm 2.5 \%, p<0.0001 ; \mathrm{HI}+\mathrm{Ox}$ IGF-1-A: $121.4 \pm 4.4, p<0.0002$, respectively) in comparison to both the $\mathrm{Nx}$ and injured controls, indicating a stimulation of this neuronal precursor marker under these conditions.

When analyzed by ICC and confocal microscopy (Figure 4E), an important reduction in total cell number (estimated by DAPI staining) was observed when cultures were exposed to $\mathrm{HI}+\mathrm{Ox}$ conditions (Figure 4Ee) in comparison to the Nx controls (Figure 4Ea). Moreover, relevant decreases in DCX-IR (Figure 4Ef) and NeuN-IR (Figure 4Eg) were found in relation to their corresponding Nx controls (Figure $4 \mathrm{~Eb}, \mathrm{c}$, respectively), and apparently the deleterious effect was more evident upon the mature neurons. As described before (Figure 2), disruption of cell interactions and clumping were also observed here (Figure 4Eh vs. Figure 4Ed). Confocal images show that treatment of the injured cells with either GH or IGF-1 prevented the damage provoked by hypoxia-ischemia and stimulated the survival of both DCX-IR and NeuN-IR neurons, as shown in Figure 4Ej,n,l and Figure $4 \mathrm{Ek}, \mathrm{o}, \mathrm{p}$, respectively. 


\section{Western blot}

A)

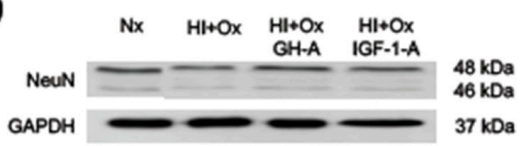

B)

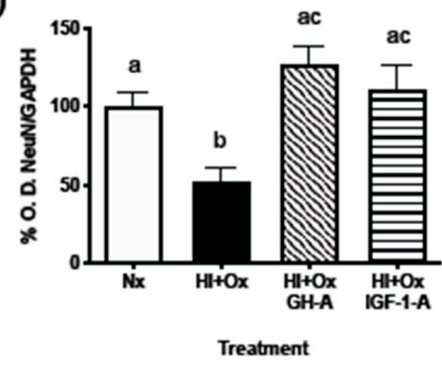

E)

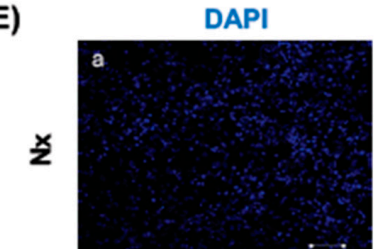

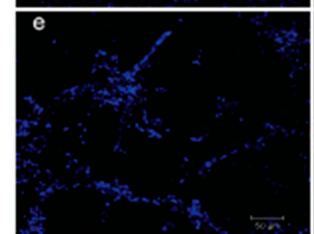
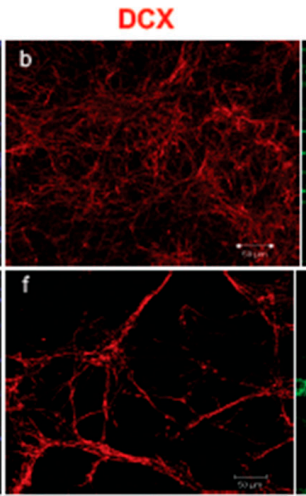

\section{喜重}
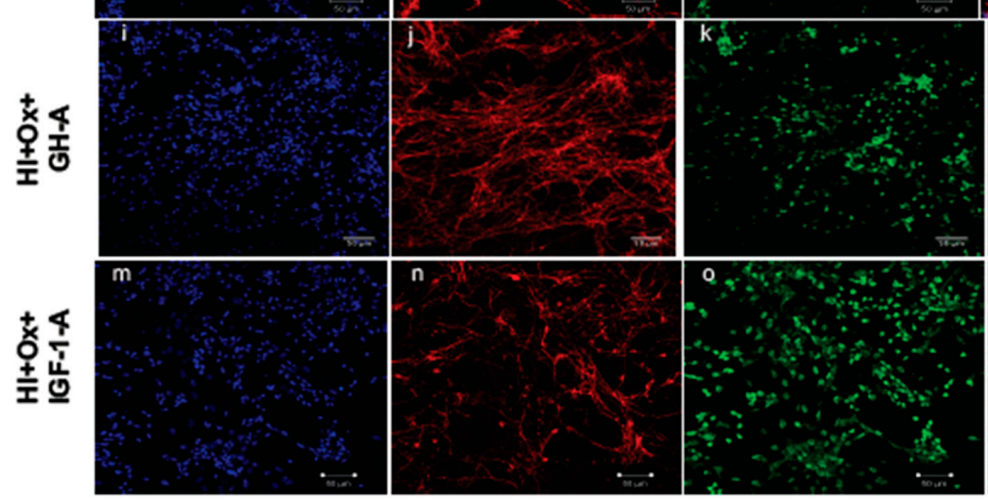

C)

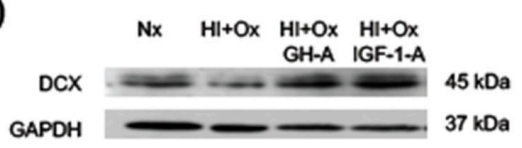

D)

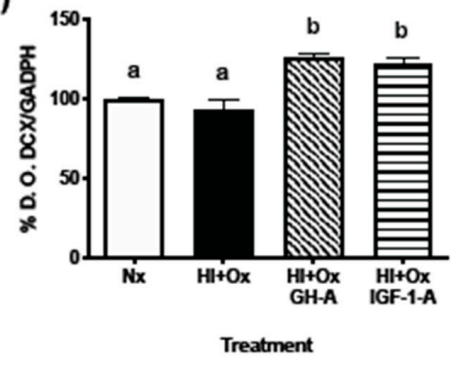

NeuN Merge
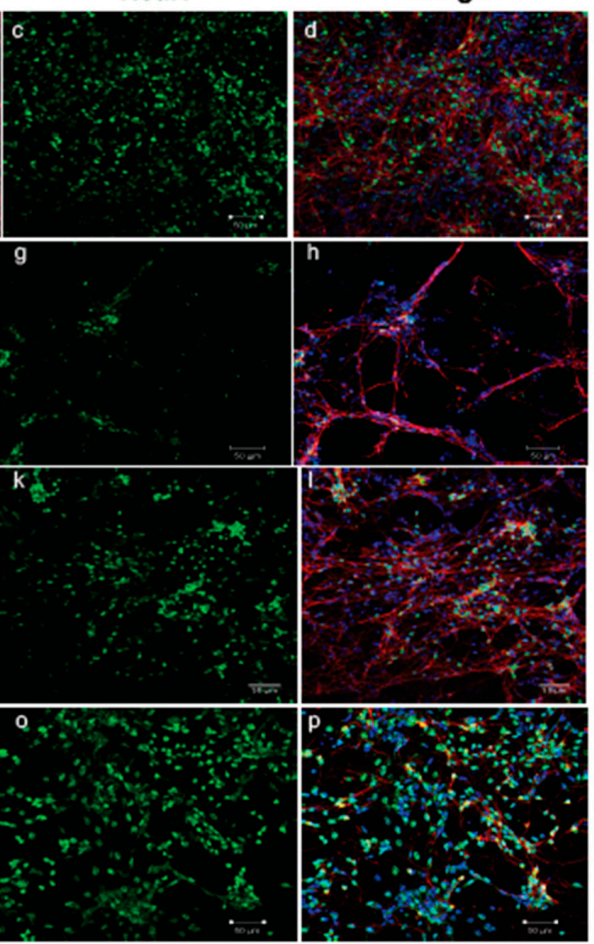

Figure 4. Treatments with GH or IGF-1 increase the survival of mature neurons and neural precursors after a hypoxicischemic injury in primary cerebellar cultures. Cells were maintained under either normoxic conditions (Nx), submitted to hypoxic-ischemic injury for $12 \mathrm{~h}(\mathrm{HI})$ and then reoxygenated for $24 \mathrm{~h}(\mathrm{HI}+\mathrm{Ox})$, or treated with $1 \mathrm{nM}$ GH or $40 \mathrm{nM}$ IGF-1 after (denoted by A) $12 \mathrm{~h}$ of $\mathrm{HI}$, along the $24 \mathrm{~h}$ of reoxygenation period (HI + Ox GH-A; HI + Ox IGF1-A). The upper panels show Western blots with specific immunoreactive bands corresponding to either neuronal nuclei protein (NeuN, panel (A)), a marker for mature neurons, or doublecortin (DCX, panel (C)), a marker for neuronal precursors, and GAPDH (panels $(\mathbf{A}, \mathbf{C}))$, used as loading control. Panels (B,D) show the densitometric (\%O.D.) analysis of changes observed in panels (A,C). Both GH and IGF-1 treatments induced a significant increase of NeuN-IR (panel (B)) and DCX-IR (panel (D)). Bars represent the mean \pm SEM, $n=4$ independent experiments performed in duplicate. Groups with different letters are significantly different by one-way ANOVA and Tukey's post hoc test $(p<0.01)$. (E) Representative confocal ICC images show the effects of different incubation conditions upon NeuN-IR, DCX-IR, and cell number (DAPI) in primary cerebellar cell cultures exposed to Nx (Ea-d), HI + Ox (Ee-h), HI + Ox plus GH treatment ((Ei-1) HI + Ox GH-A), and HI + Ox plus IGF-1 treatment $(\mathbf{E m}-\mathbf{p}), \mathrm{HI}+\mathrm{Ox}$ IGF1-A). (Ea,e,i,m) shows cell nuclei counterstained with DAPI to determine the number of cells present in cultures; (Eb,f,j,n) shows DCX-IR; (Ec,g,k,o) shows NeuN-IR; and (Ed,h,l,p) shows the co-localization of NeuN-IR, DCX-IR, and DAPI in the merged images. Scale bar: $50 \mu \mathrm{m}$. 


\subsection{Effects of GH and IGF-1 Administration after Hypoxia-Ischemia upon PI3K/Akt, MAPK/ERK1/2, and Bcl-2 Pathways}

The effects of HI + Ox injury, as well as further treatment with GH or IGF-1, upon activation of several signaling pathways involved in cell survival, were evaluated by Western blotting, where we analyzed the phosphorylation ratio of Akt and ERK1/2, and the expression of Bcl-2 immunoreactivities. As it is shown in Figure $5 \mathrm{~A}, \mathrm{~B}$, the ratio of optical density (\% O.D.) between pAkt(S473)/GAPDH significantly decreased in the HI + Ox group $(67.6 \pm 7.8 \%, p<0.005)$ in comparison with the Nx group $(100 \pm 1.8 \%)$. On the other hand, the addition of GH resulted in a meaningful increase of Akt phosphorylation ( $\mathrm{HI}+\mathrm{Ox}$ $\mathrm{GH}-\mathrm{A}, 113.2 \pm 8.9 \%, p<0.0002)$ in relation to the injured group, while the administration of IGF-1 restored pAkt to Nx levels, but this was not significantly different from the damaged control (HI + Ox IGF-1-A, 102.5\% $\pm 16.8 \%$ ). In contrast, Figure 5C,D shows that exposure of cerebellar cultures to $\mathrm{HI}+\mathrm{Ox}$ conditions provoked a significant increase in the ratio of phosphorylated ERK1/2/GADPH $(141.6 \pm 10.8 \%, p<0.03)$ in comparison to the Nx control $(100 \pm 5.5 \%)$, and GH treatment did not show any effect (HI + Ox GH-A, $143.4 \pm 15.4 \%)$ in relation to the injured group but was significantly different $(p<0.02)$ from the normal controls. Instead, IGF-1 treatment significantly decreased the ratio of pERK1/2 (HI + Ox IGF-1-A, $93.6 \pm 17.6 \%, p<0.02)$ in relation to the $\mathrm{HI}+$ Ox group. Figure $5 \mathrm{E}, \mathrm{F}$ shows that the antiapoptotic Bcl-2-IR band did not change in the HI + Ox group (94.6 $\pm 5.5 \%)$ in relation to the Nx control $(99.1 \pm 2.6 \%)$. However, Bcl-2-IR was significantly increased with GH treatment $(\mathrm{HI}+\mathrm{Ox} \mathrm{GH}-\mathrm{A}, 127.7 \pm 8.8 \%, p<0.01)$ in comparison to both $\mathrm{Nx}$ and injured groups, whereas IGF-1 administration had no significant effects (HI + Ox IGF-1-A, $114.3 \pm 9.7 \%$ ) between groups.
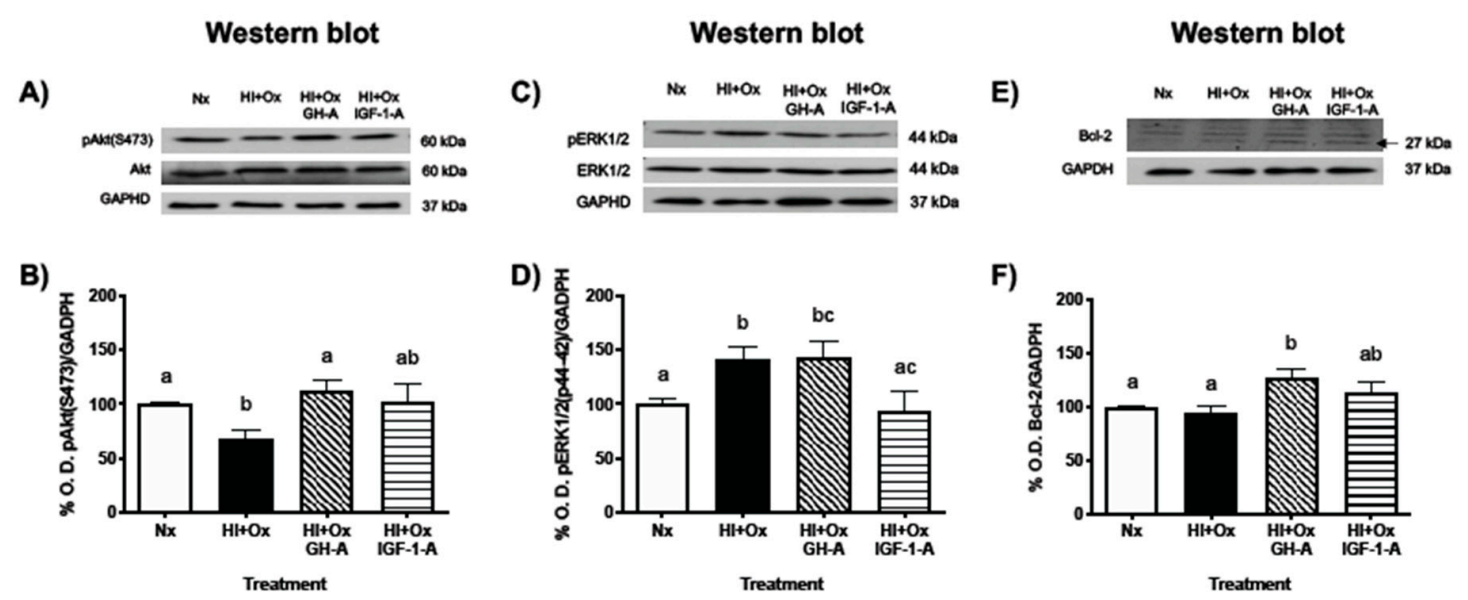

Figure 5. Effects of GH and IGF-1 treatments upon activation of the PI3K/Akt and MAPK/ERK1/2 signaling pathways and $\mathrm{Bcl}-2$ expression after a hypoxic-ischemic injury in primary cerebellar cultures. Cells were maintained under either normoxic conditions $(\mathrm{Nx})$, submitted to hypoxic-ischemic injury for $12 \mathrm{~h}(\mathrm{HI})$ and then reoxygenated for $24 \mathrm{~h}(\mathrm{HI}+\mathrm{Ox})$, or treated with $1 \mathrm{nM} \mathrm{GH}$ or $40 \mathrm{nM}$ IGF-1 after (denoted by A) $12 \mathrm{~h}$ of $\mathrm{HI}$, along the $24 \mathrm{~h}$ of reoxygenation period (HI $+\mathrm{Ox}$ GH-A; HI + Ox IGF-1-A). The upper panels show Western blots with specific immunoreactive bands corresponding to the following proteins: (A) total Akt (60 kDa) or pAkt (S473, $60 \mathrm{kDa})$; (C), ERK1/2 (44 kDa) or pERK1/2 (T202/Y204, 44 kDa); (E), Bcl-2 (27 kDa); and GAPDH (panels (A,C,E), $37 \mathrm{kDa}$ ) as loading control. (B,D,F) show densitometric (\% O.D.) analysis of changes observed in (A,C,E). Bars represent the mean $\pm \mathrm{SEM}, n=5$ independent experiments performed in duplicate. Groups with different letters are significantly different by one-way ANOVA and Tukey's post hoc test $(p<0.01)$.

2.6. Effects of Acute (HI) and Subacute $(H I+O x)$ Injury upon Local GH, GHR, IGF-1 and IGF-1R mRNAs Expression in Primary Cerebellar Cultures

Figure 6A shows that local GH mRNA expression was significantly increased mainly under the subacute injury condition ( $\mathrm{HI}+\mathrm{Ox}, 3.2 \pm 0.7$-fold, $p<0.006)$ as compared with $\mathrm{Nx}$ control (1.1 \pm 0.1 -fold), whereas as shown in Figure $6 \mathrm{~B}$, the GH receptor (GHR) mRNA 
expression was appreciably augmented during the acute injury phase (HI, $2.3 \pm 0.1$-fold, $p<0.0001$ ), and then it significantly diminished after reoxygenation ( $\mathrm{HI}+\mathrm{Ox}, 0.47 \pm 0.06$-fold, $p<0.001)$, in relation with the Nx group (1.04 \pm 0.05 -fold). On the other hand, under HI conditions, the expression of local IGF-1 ( $0.62 \pm 0.03$-fold, $p<0.003$, Figure $6 \mathrm{C})$ and IGF-1R $(0.78 \pm 0.05$-fold, $p<0.05$, Figure $6 \mathrm{D}) \mathrm{mRNAs}$ were substantially decreased, as compared to the Nx control (1.04 \pm 0.06 -fold and $1.04 \pm 0.05$-fold, unpaired t-test, respectively) Conversely, during the subacute phase injury phase (HI + Ox), the expression of both IGF-1 $(2.5 \pm 0.46$-fold, $p<0.0005$, Figure $6 \mathrm{C})$ and IGF-1R $(1.7 \pm 0.2$-fold, $p<0.003$, Figure $6 \mathrm{D})$ mRNAs significantly increased, in relation to the Nx controls.

A)

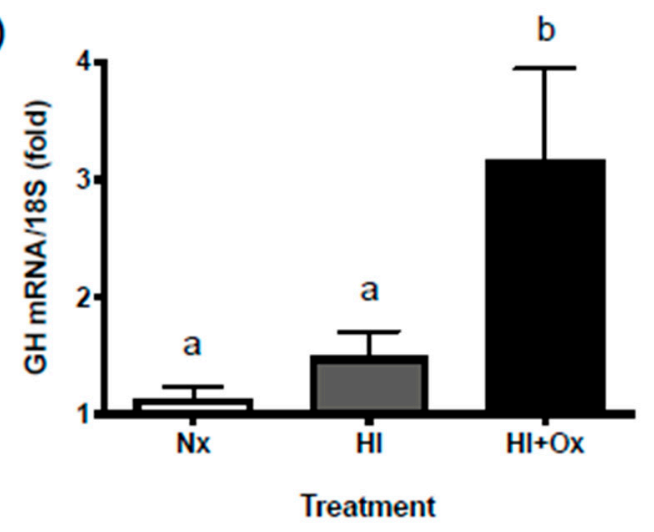

C)

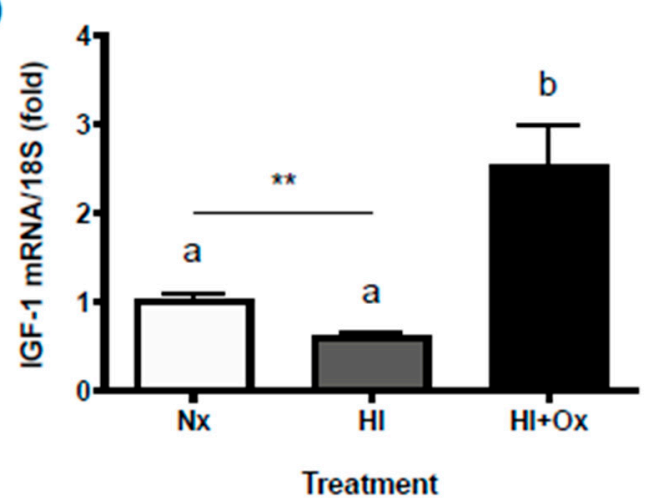

B)

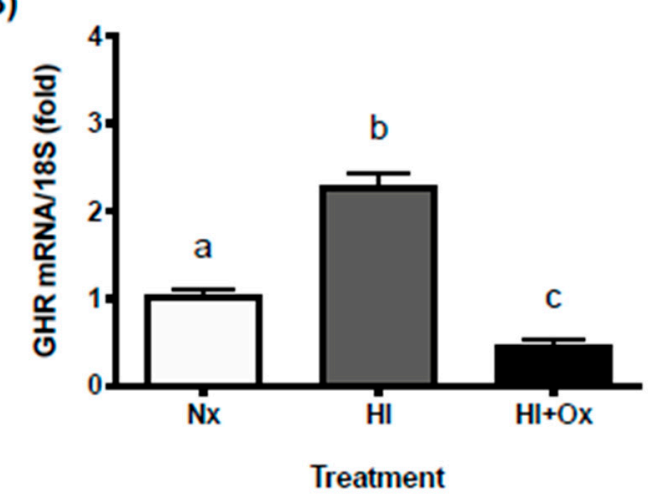

D)

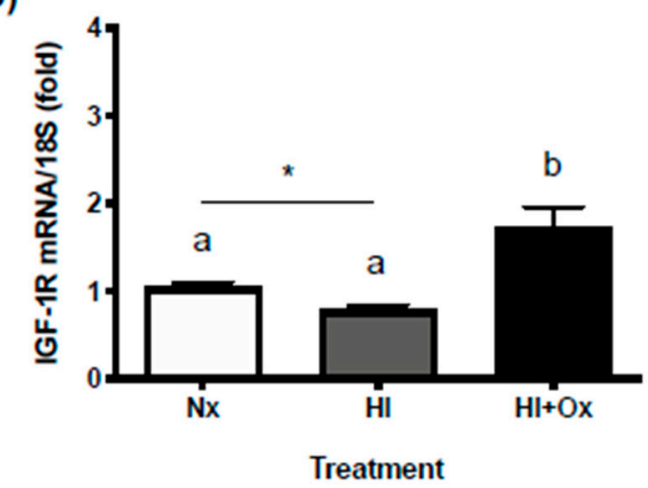

Figure 6. Expression of GH, GHR, IGF-1, and IGF-1R mRNAs in primary cerebellar cultures exposed to normoxic (Nx), acute hypoxia-ischemia (HI) injury, or subacute hypoxia-ischemia (HI + Ox) injury. The relative expression of (A) GH, (B) GHR, (C) IGF-1, and (D) IGF-1R mRNAs was determined by qPCR and corrected by the threshold cycle (CT) using the formula $2^{-\triangle \Delta C T}$. Ribosomal $18 \mathrm{~S}$ RNA was used as the housekeeping gene control. Bars represent the mean $\pm \mathrm{SEM}, n=3$ independent experiments by duplicate. Groups with different letters are significantly different by one-way ANOVA and Tukey's post hoc test $(p<0.01)$. An unpaired Student's $t$ test was used to evaluate the effect of Nx versus HI conditions (panels $(\mathbf{C}, \mathbf{D}))$. Asterisks indicate significant differences between groups $\left({ }^{*} p<0.05,{ }^{* *} p<0.003\right)$.

2.7. Effects from GH and IGF-1 Gene Silencing by Specific siRNAs in Cerebellar Cell Cultures under Normal and Hypoxic-Ischemic Conditions, upon GH, GHR, IGF-1 and IGF-1R mRNAs Expression

To analyze the involvement of locally produced GH and IGF-1 in the protective response against $\mathrm{HI}$ injury, their respective mRNA expression was blocked using specific small-interfering RNAs (siRNAs). The mediated downregulation of both siGH and siIGF-1 in cerebellar cultures was determined by real-time PCR (qPCR) after $48 \mathrm{~h}$ post-transfection of the corresponding siRNAs. 
Initially, the efficacy of mRNA knock-down was studied under Nx incubation conditions. A random oligonucleotide (Nx scramble) was used as an additional siRNA (negative) control. Results showed that, as expected, administration of siGH significantly reduced the expression of cerebellar GH mRNA $(0.48 \pm 0.04$-fold, $p<0.004$, Figure 7A), and also of IGF-1 mRNA $(0.61 \pm 0.07$-fold, $p<0.009$, Figure 7E), as compared with their corresponding Nx siRNA controls (1.13 \pm 0.15 -fold, and $1.16 \pm 0.13$-fold, respectively). Moreover, transfection with siGH induced a substantial decrease of GHR mRNA expression ( $0.61 \pm 0.07$-fold, $p<0.004$, Figure 7C) in relation to its control group (1.2 \pm 0.12 -fold), but it had no effect upon IGF-1R mRNA expression (1.34 \pm 0.32-fold, Figure 7G), which was no different from the Nx siRNA control (1.3 \pm 0.18 -fold). On the other hand, as anticipated, transfection with siIGF-1 significantly lowered the expression of IGF-1 mRNA $(0.52 \pm 0.08$-fold, $p<0.0004$, Figure 7E) in relation to the corresponding controls, but it induced a considerable increase of GH mRNA expression (1.76 \pm 0.4 -fold, $p<0.04$, Figure 7A), compared to its Nx control $(1.05 \pm 0.07$-fold), although it was not statistically different from the Nx siRNA group $(1.13 \pm 0.15$-fold). Additionally, silGF-1 provoked a clear reduction of GHR mRNA expression $(0.67 \pm 0.06$-fold, $p<0.01$, Figure $7 \mathrm{C})$ relative to the controls, but it had no effect upon IGF-1R mRNA expression (0.93 \pm 0.11 -fold, Figure $7 G)$.

Normoxia

A)

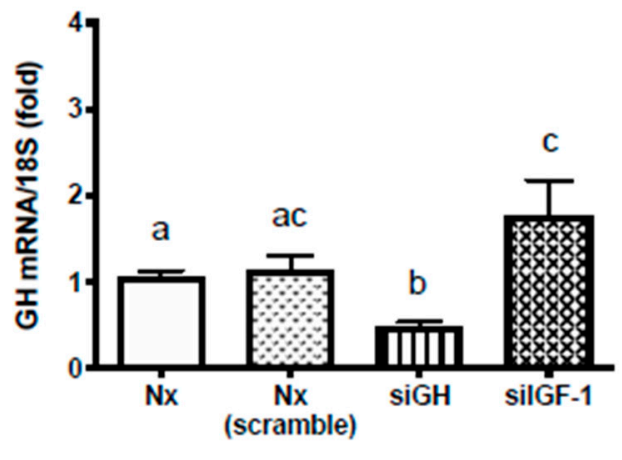

Treatment

C)

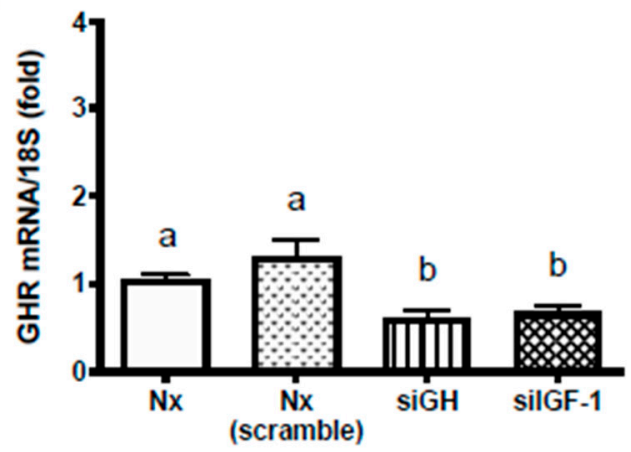

Treatment

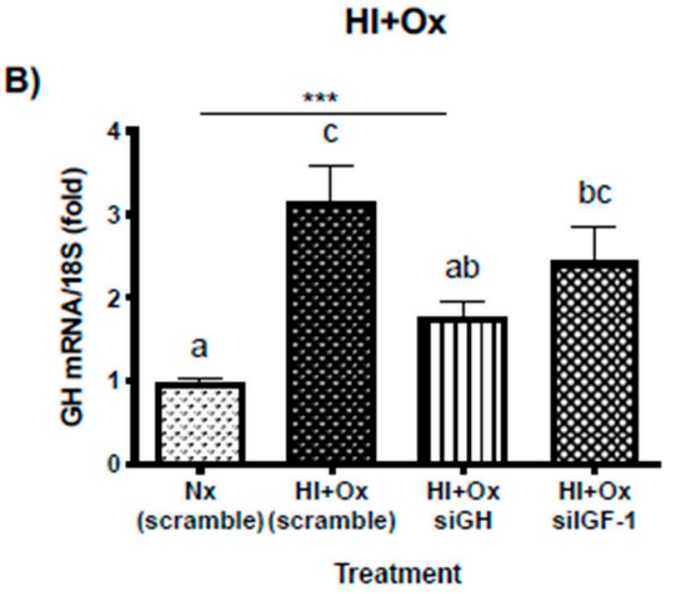

D)

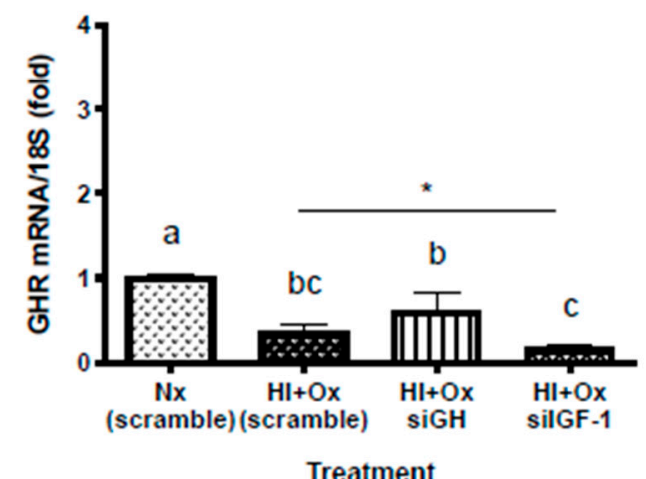

Figure 7. Cont. 
Normoxia

E)

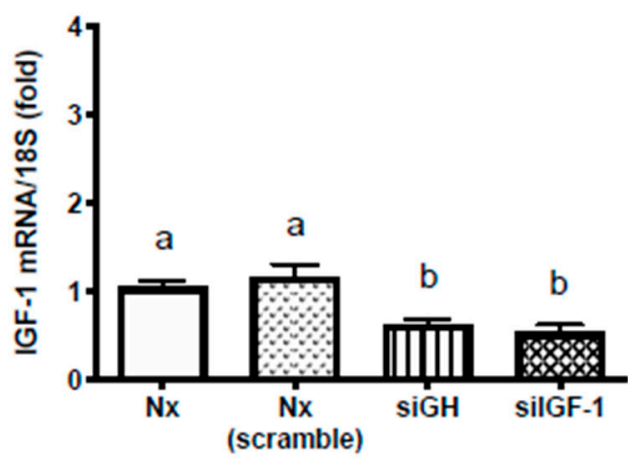

Treatment

G)

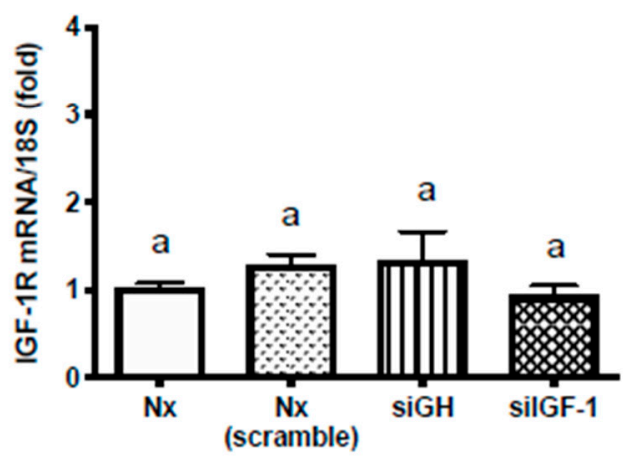

Treatment

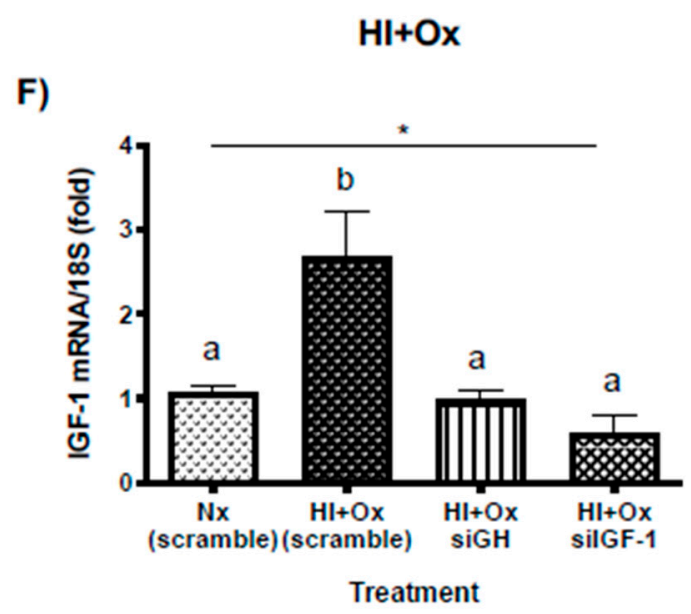

H)

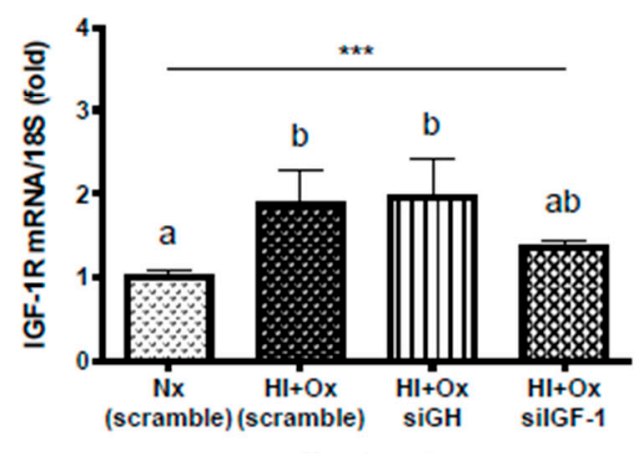

Treatment

Figure 7. Effects of transfecting specific siRNAs (siGH or siIGF-1) to knock-down GH or IGF-1 gene expression in the primary cerebellar cultures exposed to either normoxic $(\mathrm{Nx}$, panels $(\mathbf{A}, \mathbf{C}, \mathbf{E}, \mathbf{G}))$ or subacute hypoxic-ischemic injury $(\mathrm{HI}+\mathrm{Ox}$, panels $(\mathbf{B}, \mathbf{D}, \mathbf{F}, \mathbf{H})$ ) conditions, upon local expression of GH (panels (A,B)), GHR (panels (C,D)), IGF-1 (panels (E,F)), and IGF-1R (panels (G,H)) mRNAs. Nonsilencing siRNA (scramble) was transfected to cells as an additional control. The relative expression was determined by qPCR and corrected by the threshold cycle (CT) using the formula $2^{-\Delta \Delta C T}$. Ribosomal $18 \mathrm{~S}$ RNA was used as housekeeping gene control. Bars represent the mean $\pm \mathrm{SEM}, n=4$ independent experiments by duplicate. Groups with different letters are significantly different by one-way ANOVA and Tukey's post hoc test $(p<0.01)$. An unpaired Student's $t$ test was used to evaluate the effect of Nx scramble versus HI + Ox siGH conditions (panel (B)), $\mathrm{HI}+\mathrm{Ox}$ scramble versus HI + Ox siIGF-1 (panel (D)), and Nx scramble versus HI + Ox siIGF-1 (panels $(\mathbf{F}, \mathbf{H})$ ). Asterisks indicate significant differences between groups $\left({ }^{*} p<0.05, * * * p<0.001\right)$.

Later, the effect of local GH and IGF-1 mRNAs knockdown was studied under HI + Ox conditions. In agreement with previous results (Figure 6A), the exposition of scrambletransfected cerebellar cells to hypoxic-ischemic injury resulted in a very strong and meaningful rise in the local expression of GH mRNA (HI + Ox scramble, $3.16 \pm 0.41$-fold, $p<0.0001$, Figure $7 \mathrm{~B}$ ) as compared to the Nx scramble group ( $0.97 \pm 0.04$-fold). In addition, under these conditions, significant increases in the expression of IGF-1 (2.68 \pm 0.51 -fold, $p<0.0008$, Figure 7F) and IGF-1R $(1.89 \pm 0.37$-fold, $p<0.04$, Figure 7H) mRNAs were found, in comparison to their corresponding $\mathrm{Nx}$ scramble controls. In contrast, $\mathrm{HI}+\mathrm{Ox}$ scramble conditions provoked a substantial reduction of GHR mRNA expression $(0.37 \pm 0.07$-fold, $p<0.0001$, Figure 7D). Transfection of cerebellar cells with siGH provoked a significant diminution of GH mRNA expression ( $\mathrm{HI}+\mathrm{Ox}$ siGH, $1.77 \pm 0.18$-fold, $p<0.005$, Figure 7B) with respect to the $\mathrm{HI}+\mathrm{Ox}$ scramble group response, although it did not reach the levels obtained in the Nx scramble control $(p>0.001$ unpaired $t$ test). In addition, under these conditions, the expression of IGF-1 mRNA was appreciably decreased ( $0.98 \pm 0.1$-fold, $p<0.005$, Figure 7F) in comparison to the $\mathrm{HI}+$ Ox group, and it returned to similar levels as in the $\mathrm{Nx}$ 
scramble control. The knockdown of GH by siGH maintained the GHR mRNA expression reduced $(0.62 \pm 0.2$-fold, $p<0.01$, Figure $7 \mathrm{D})$ in relation to the Nx scramble control, and it was no different from the HI + Ox group, whereas the expression of IGF-1R was similar $(1.97 \pm 0.42$-fold, $p<0.02$, Figure $7 \mathrm{H})$ to that observed in the hypoxic-ischemic control, and it remained significantly increased in comparison to the $\mathrm{Nx}$ scramble group. On the other hand, the transfection with siIGF-1 effectively provoked a substantial decrease of IGF-1 mRNA expression $(0.59 \pm 0.2$-fold, $p<0.0002$, Figure 7F) in comparison to the $\mathrm{HI}+\mathrm{Ox}$ scramble group, and to levels lower than the Nx scramble control $(p<0.02$, unpaired $t$ test). The knockdown of IGF-1 did not affect the rise of GH mRNA expression produced by hypoxic-ischemic conditions, which was kept significantly augmented ( $2.43 \pm 0.42$-fold, $p<0.0008$, Figure 7B) in comparison to the Nx scramble control. In addition, siIGF-1 provoked a meaningful reduction of GHR mRNA expression $(0.17 \pm 0.03$-fold, $p<0.0001$, Figure 7D) with respect to Nx scramble and HI + Ox scramble ( $p<0.02$, unpaired $t$ test) conditions as well as to the $\mathrm{HI}+\mathrm{Ox}$ siGH group. Finally, the expression of IGF-1R mRNA was different $(1.37 \pm 0.06$-fold, Figure $7 \mathrm{H})$ from Nx scramble $(p<0.009$, unpaired $t$ test) but not from $\mathrm{HI}+$ Ox scramble group.

\subsection{Role of Locally-Expressed and Exogenously-Added GH and IGF-1 in the Neuroprotective Response to Hypoxic-Ischemic Injury in Primary Cerebellar Cultures}

Figure $8 \mathrm{~A}$ shows that both $\mathrm{HI}+\mathrm{Ox}$ and $\mathrm{HI}+\mathrm{Ox}$ scramble groups provoked a substantial decrease of cell viability $(54.08 \pm 2.1 \%, p<0.0001$, and $57.6 \pm 5.7 \%, p<0.0001$, respectively) as compared to the $\mathrm{Nx}$ control $(100 \pm 4.5 \%)$. Moreover, knocking-down $\mathrm{GH}$ mRNA expression provoked a further significant reduction in cell viability $(35.8 \pm 2.1 \%)$ in comparison with the $\mathrm{HI}+\mathrm{Ox}$ scramble group $(p<0.01)$ and with the Nx control $(p<0.0001)$. However, treatment with exogenous $\mathrm{rcGH}(1 \mathrm{nM})$ partially restored and appreciably increased cell viability $(\mathrm{HI}+\mathrm{Ox} \mathrm{siGH}+\mathrm{GH}-\mathrm{A}, 45.3 \pm 3.8 \%, p<0.02$, unpaired $t$ test). Likewise, the addition of external IGF-1 $(40 \mathrm{nM})$ promoted a partial rescue and significant increase of cell viability (HI + Ox siGH + IGF-1-A, $53.7 \pm 3.2 \%, p<0.0001)$ in comparison with the $\mathrm{HI}+\mathrm{Ox}$ siGH group. Figure $8 \mathrm{C}$ shows that the exposure of cells to $\mathrm{HI}+\mathrm{Ox}$ and $\mathrm{HI}+\mathrm{Ox}$ scramble conditions induced a strong and significant necrotic response ( $606 \pm 116.7 \%, p<0.0007$, and $474.0 \pm 37.3 \%, p<0.05$, respectively), in comparison to the Nx control $(100 \pm 5.4 \%)$, as determined by LDH release to the culture media. Interestingly, knocking-down local GH expression further increased the necrotic response almost twice $(1,011 \pm 276.6 \%, p<0.02)$ in relation to that observed in the HI + Ox scramble group. Again, the treatment with exogenous GH or IGF-1 significantly decreased LDH release and necrosis $(320.1 \pm 25.4 \%, p<0.02$, and $421.7 \pm 62.2 \%, p<0.04$, respectively), indicating a role of these factors in rescuing cells from necrotic death.

On the other hand, as shown in Figure 8B, neither the treatment with exogenous IGF-1 (HI + Ox siIGF-1 + IGF1-A, $40.9 \pm 4.4 \%$ ) or GH (HI + Ox silGF-1 + GH-A, 41.8 $\pm 4.1 \%)$ significantly modified the deleterious effect of the knockdown of local IGF-1 expression (HI + Ox siIGF-1, $38.9 \pm 5.1 \%$ ) in comparison with the HI + Ox scramble upon cell viability ( $54.1 \pm 2.1 \%, p<0.05$, unpaired $t$ test). However, as shown in Figure $8 \mathrm{D}$, knocking-down local IGF-1 mRNA expression showed a substantial increase of necrosis $(\mathrm{HI}+\mathrm{Ox}$ silGF-1, $842.9 \pm 161.7 \%, p<0.006$, unpaired $t$ test) in relation to the $\mathrm{HI}+\mathrm{Ox}$ scramble group $(474 \pm 37.3 \%)$ and to Nx conditions $(100 \pm 5.4 \%, p<0.0001)$. Treatment with either IGF-1 (HI + Ox siGH + IGF-1-A, $498.2 \pm 39.6 \%, p<0.041)$ or GH (HI + Ox siGH $+\mathrm{GH}-\mathrm{A}, 494.6 \pm 57.1 \%, p<0.02)$ significantly reduced $\mathrm{LDH}$ release in comparison to the $\mathrm{HI}+\mathrm{Ox}$ siIGF-1 group, indicating that these factors partially rescued the cells from necrosis. 

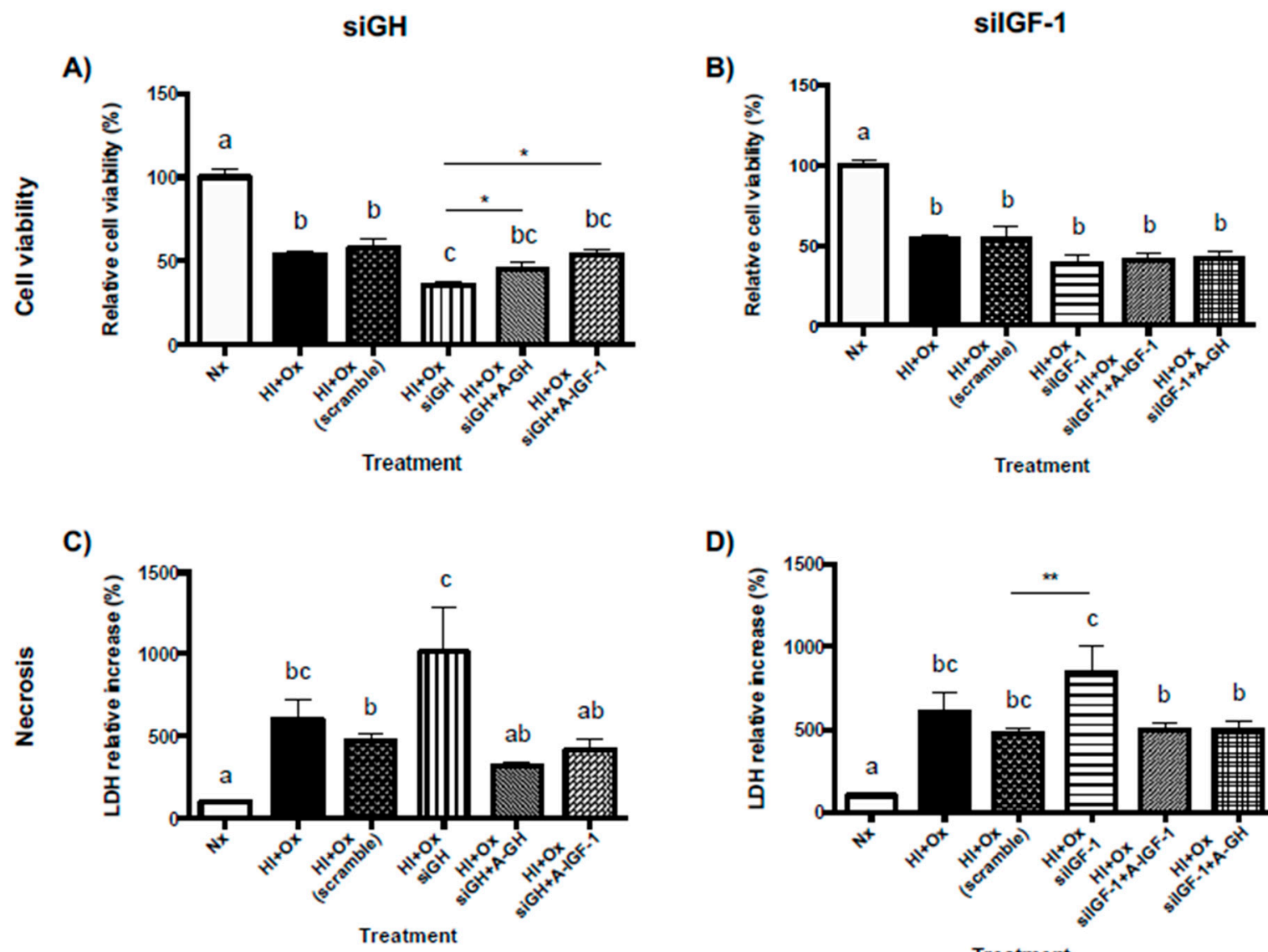

D)

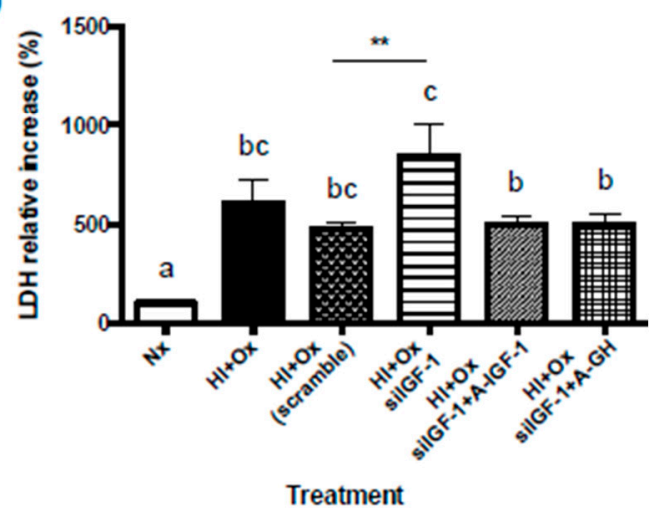

Figure 8. Neuroprotective actions of GH treatment applied after an acute hypoxic-ischemic injury (HI) upon cell viability and necrosis are partially mediated by IGF-1. Cerebellar cells that were transfected with either siGH (panels (A,C)) or siIGF-1 (panels (B,D)) were treated with $1 \mathrm{nM} \mathrm{GH}$ or $40 \mathrm{nM}$ IGF-1 in a subacute hypoxic-ischemic injury (HI + Ox). Nonsilencing siRNA (scramble) was transfected to cells as an additional control. Cell viability was evaluated by the MTT assay (panels $(\mathbf{A}, \mathbf{B}))$, whereas cell necrosis was determined by LDH activity released to the culture media (panels (C,D)). Bars represent the mean \pm SEM, $n=4$ independent experiments by duplicate. Groups with different letters are significantly different by one-way ANOVA and Tukey's post hoc test $(p<0.01)$. An unpaired Student's $t$ test was used to compare $\mathrm{HI}+\mathrm{Ox}$ siGH versus $\mathrm{HI}+\mathrm{Ox}$ siGH GH-A and HI + Ox siGH IGF-1-A groups (panel (A)) and HI + Ox scramble versus HI + Ox siIGF-1 groups (panels $(\mathbf{B}, \mathbf{D}))$. Asterisks indicate significant differences $\left({ }^{*} p<0.05,{ }^{* *} p<0.006\right)$.

\section{Discussion}

Here, we show that the primary neuronal cultures from cerebellum (neuronal precursors and mature neurons) that were exposed to hypoxia-low glucose or oxygenation damage improve their viability and survival parameters when they are incubated in the presence of GH and IGF-1. In addition, our findings support that the endogenous expression of GH and IGF-1 during an acute hypoxic-ischemic injury is essential to maintaining cell survival. Moreover, we demonstrated that the GH-dependent IGF-1 mRNA expression during an acute injury partially mediates the protective effects of GH in primary cerebellar neurons. Taken together, these results provide further evidence for the autocrine/paracrine mechanisms of GH and IGF-1 that mediate their neuroprotective effects.

Our findings that the expression of the transcription factor hypoxia-inducible factor $1 \alpha$ (HIF-1 $\alpha$ ) increases after a hypoxia-ischemia insult supports that cerebellar primary neurons are responsive to the injury conditions and are consistent with previous studies, both in vivo and in vitro, showing that mouse cortical neurons exposed to hypoxic conditions showed an increase in this factor [32-34]. It is well known that the increase of HIF-1 $\alpha$ is a characteristic response of cells to hypoxia and ischemia during early development [35,36], 
which could be associated with its neuroprotective effects [37], although it has also been described that the increase has neurotoxic effects [38,39]. Our results show that cell viability decreased after exposure to hypoxia-ischemia and reoxygenation while cell death parameters (apoptosis and necrosis) increased, which suggests that the intrinsic factors of primary cerebellar neurons are not sufficient to decrease the cell damage progression.

We previously found that GH treatment improves the viability and survival parameters of cerebellar primary neurons when it is added during the hypoxia-ischemia insult [11]. In order to know whether $\mathrm{GH}$ is also capable of conferring neuroprotection during the damage produced by reoxygenation and to investigate the role that IGF-1 plays in this process, in the present work, we analyzed the phase-dependent impact of GH and IGF-1 on neuronal cell death. Our results show that both GH and IGF-1 improve viability and inhibit cell death in both stages of cell injury, which agree with previous studies reporting that GH and IGF-1 have important roles as neurotrophic factors [3,11,18,40-42].

It was described that the severity of damage caused by hypoxia depends on the state of neuronal differentiation [43]. To extend our understanding of the mechanisms behind the positive effects of GH and IGF-1 on cell survival, we also evaluated the impact of GH and IGF- 1 on the mature and immature neuronal populations. We observed a significant reduction in the mature neural cells (NeuN positive) compared with the immature population (DCX positive) under $\mathrm{HI}+$ Ox conditions, which is consistent with our previous observation [11]. Specifically, the susceptibility of the NeuN positive cells to death mainly by necrosis, along with apoptosis, due to $\mathrm{HI}+\mathrm{Ox}$, is related to the depletion in cellular ATP levels [18,43]. Interestingly, we observed a significant increment in the NeuN positive and DCX positive cells from the primary cerebellar cell cultures treated with GH and IGF-1 during the oxygenation phase. These observations are consistent with previous reports describing that $\mathrm{GH}$ has protective actions in both mature neurons $[44,45]$ and in primary neurospheres derived from embryonic neural stem cells of mouse [46,47]. SanchezBezanilla et al. [48] observed that GH promotes cell proliferation (BrdU-positive cells) within the peri-infarct regions in stroke mice. Furthermore, they tracked the fate of these proliferating cells and found an increase in the number of NeuN and DCX positive cells. These findings further support that GH plays an important role in neurogenesis in a stroke model. Similarly, Lin et al. [49] found an IGF-1-dependent increase in the number of DCX and NeuN positive cells and concluded that in addition to its antiapoptotic effects, IGF-1 acts as a mitogenic agent in a neonatal rat hypoxic-ischemic model of brain injury, which is in accordance with the amount of evidence supporting the claim that IGF-1 plays a key role in the proliferation and maturation of neurons, both in vivo and in vitro [50,51].

The mechanisms by which GH exerts its protective effects include the suppression of apoptotic related proteins (Bax) or increasing the expression of antiapoptotic proteins such as Bcl2 and activation of the PI3K/AKT signaling pathway [11,41,52]. Our analysis confirmed that AKT phosphorylation, which decreased in hypoxic condition, is recovered by $\mathrm{GH}$ treatment, while Bcl2 expression increases in response to $\mathrm{GH}$. In addition, we found that although these were not statistically significant, the absolute levels of phosphorylated AKT and Bcl2 expression increased with the IGF-1 treatment, which is consistent with the numerous evidence, indicating that IGF-1 is an activator of the PIK3/AKT signaling pathway as a mechanism to promote cell survival and inhibit apoptosis [14,20,53-57].

The activation of the ERK1/2 signaling pathway is recognized as a response of neurons displaying signs of damage after a hypoxic-ischemic insult [58-60] and our results confirmed that ERK $1 / 2$ phosphorylation is increased in cerebellar primary neurons during reoxygenation. However, we observed that ERK phosphorylation does not increase with $\mathrm{GH}$ treatment beyond the point that it increases with the oxygenation damage. This may indicate that the activity of the ERK1/2 signaling pathway observed during the cell damage is the maximum response, and this cannot be enhanced by GH treatment. Conversely, although previous studies demonstrated that IGF-1 is a strong activator of the ERK1/2 pathway $[56,57]$, we found that IGF-1 treatment blocked ERK1/2 phosphorylation induced 
by neuronal damage. This suggests that IGF-1 may exert its effects at other time points not assessed or that treatment saturates the ERK1/2 response.

We analyzed changes in the expression of GH and IGF-1 mRNAs (and their respective receptors) in order to study the role of the endogenous GH-IGF-1 system during hypoxia and oxygenation damage. Our results showed that this hormonal system increases its local expression in response to cell damage, mainly during reoxygenation, although it is important to note that GHR expression decreases in this condition, perhaps as a negative feedback mechanism. These results are consistent with the numerous evidence that indicates that the endogenous expression of GH and IGF-1 during a damaging condition, whether due to hypoxia [11,61], excitotoxicity [12,62], or trauma [13,63], plays a critical role within the mechanisms triggered by neurons to preserve their survival and viability.

The binding of GH to its specific receptor causes an increase in the synthesis of IGF-1, which is released and, in turn, binds to its specific receptor. Thus, GH has direct effects and other effects mediated by IGF-1 [20,64,65]. By silencing GH and IGF-1 mRNAs, we tested how the GH-IGF-1 axis was affected by GH or IGF-1 deficiency and how this impacted the survival parameters of primary cerebellar neurons exposed to hypoxic and oxygenation injury. We confirmed that GH silencing leads to the downregulation of GHR and IGF-1 mRNAs, while IGF-1 deficiency impacts negatively on the GHR mRNA levels. These findings are consistent with previous reports [66-68] which demonstrated that GH deficiency in parallel affects the expression of its receptor. On the other hand, we discovered that the effect of oxygenation damage on the increased expression of IGF-1 is completely blocked by GH silencing, while the silencing of IGF-1 had no impact on the hypoxiadependent $\mathrm{GH}$ induced expression. These findings demonstrated that the protective response of the endogenous GH-IGF-1 system depends, initially, on the expression of $\mathrm{GH}$, which support the hypothesis that, in addition to the endocrine contribution of $\mathrm{GH}$, the autocrine-paracrine mechanisms of GH also play an important role during the neuroprotective response of cerebellar neurons.

Our findings on cell viability and necrosis show that GH deficiency exacerbates the damage produced by oxygenation (seen as relative cell viability and LDH release), which is blocked by GH or IGF-1 exogenous treatment. Previous works by our group [11,17] and others $[63,69]$ have pointed out the importance of $\mathrm{GH}$ as a neurotrophic factor, which have direct effects and other effects mediated by IGF- 1 and other neurotrophins, including BDNF, NT3, or VEGF $[7,11,63,69]$. This explains our results, which show that IGF-1deficient neurons treated with GH improve their viability, likely through the regulation of other neurotrophins. Intriguingly, GH or IGF-1 replacement treatment in IGF-1 silencing neurons also rescued neurons from oxygenation damage (seen as LDH release), which is further evidence that IGF-1 is important during GH-mediated neuroprotection, but that $\mathrm{GH}$ can also trigger other mechanisms to confer neuroprotection.

Taken together, our findings confirm that cerebellar neurons in damaged conditions trigger protection mechanisms that include an increase in GH and IGF-1 expression, which, through autocrine-paracrine mechanisms, contributes to preserving cell integrity and viability. Furthermore, treatment with exogenous GH represents a substantial improvement in the recovery of cell viability parameters, through mechanisms including the activation of survival signaling pathways, the positive regulation of IGF-1, and likely, the up-regulation of other neurotrophins such as BDNF, NT3, or VEGF. GH therapy is a promising opportunity to treat neural injuries and diseases; however, long-term side effects of GH treatments are still largely unknown and cannot be ruled out. Thus, this novel field of research deserves further work.

\section{Materials and Methods}

\subsection{Animals}

Pathogen-free, fertilized eggs (Gallus gallus, White Leghorn) were obtained from Pilgrim's Pride (Querétaro, México) and were incubated at $39^{\circ} \mathrm{C}$ in a humidified air chamber (IAMEX, México). The eggs were rotated one-quarter of a revolution every $50 \mathrm{~min}$ 
during incubation. The chicken embryos were sacrificed by decapitation according to a protocol approved by the bioethical committee of the Instituto de Neurobiología, UNAM, and in accordance with the Mexican official regulation (NOM-062-ZOO-1999, 10/19/2010).

\subsection{Primary Cerebellar Cell Culture}

Chicken embryos at 15 days of embryogenesis $(15 \mathrm{DE})$ were anesthetized in ovo by cooling them on ice for $5 \mathrm{~min}$ and then sacrificed by decapitation. Cerebellums were collected and put into a cold calcium/magnesium-free Hank's balanced buffer. Then, they were treated with $0.002 \%$ trypsin in DMEM (Sigma-Aldrich, St. Louis, MO, USA), at $39^{\circ} \mathrm{C}$ for $20 \mathrm{~min}$, followed by mechanical dissociation with a siliconized Pasteur pipette of narrow bore size and passed through a $40 \mu \mathrm{m}$ nylon mesh. Later, $7.5 \times 10^{5}$ cerebellar cells were plated on $50 \mathrm{\mu g} / \mathrm{mL}$ poly-L-lysine-coated 12-well culture plates and grown in a Neurobasal medium (containing $4.5 \mathrm{~g} / \mathrm{L}$ glucose) added with $2 \%$ B27 supplement, $0.5 \mathrm{mM}$ L-glutamine, and 1\% antibiotic-antimycotic mix (amphotericin B, penicillin, streptomycin; all from Gibco-BRL, Burlington, ON, Canada) at $39^{\circ} \mathrm{C}$ in a humidified atmosphere of $95 \%$ air and $5 \% \mathrm{CO}_{2}$ chamber for $48 \mathrm{~h}$ prior to treatments [11].

\subsection{Treatments}

Experimental hypoxic-ischemic (HI) conditions were induced by replacing the NeurobasalB27 culture medium with DMEM-low-glucose (LG) 1x media (1 g/L, Gibco-BRL), and the cultures were then placed in a humidified hypoxic chamber (Napco E Series, Model 302 , Tualatin, OR, USA), at $37^{\circ} \mathrm{C}$, which was previously flushed with a mixture of $5 \%$ $\mathrm{CO}_{2}$ and $95 \% \mathrm{~N}_{2}$ for $10 \mathrm{~min}$, resulting in a level of $<5 \% \mathrm{O}_{2}$ that was maintained for $12 \mathrm{~h}$ throughout the experiment, and continuously monitored with an ambient oxygen sensor (BW Technologies, Arlington, TX, USA). HI conditions were terminated by replacing the DMEM-LG medium with Neurobasal-B27 medium, and cultures were then incubated for an additional $24 \mathrm{~h}$ period of oxygenation $(\mathrm{HI}+\mathrm{Ox}$ ) under normoxic conditions ( $\mathrm{Nx}, 95 \%$ air and $5 \% \mathrm{CO}_{2}$ ).

In order to determine whether GH or IGF-1 were able to protect cerebellar cells from $\mathrm{HI}$ injury, the cultures were treated with either $1 \mathrm{nM}$ recombinant chicken growth hormone (rcGH; Revholt, PRL, Israel), or a $40 \mathrm{nM}$ recombinant human insulin-like growth factor-1 (rhIGF-1; BioVision, 4119-B9059, Malpitas, CA, USA) following the protocols depicted in Figure 1. Hormones were administered to the cell cultures in a Neurobasal medium with $0.02 \% \mathrm{~B} 27$, either during the $12 \mathrm{~h}$ acute injury (HI) incubation conditions (GH-D or IGF-1-D) or after, in the reoxygenation (sub-acute injury phase) period (HI + Ox GH-A; HI + Ox IGF-1-A) for another $24 \mathrm{~h}$. The analyses were performed after this final time interval.

\subsection{Determination of Cell Viability}

After stabilization under normal conditions for $48 \mathrm{~h}$ at $39^{\circ} \mathrm{C}$, the primary cerebellar cell cultures were exposed to the different treatments $(\mathrm{Nx}, \mathrm{HI}, \mathrm{HI}+\mathrm{Ox}$, with or without the hormones). At the end, cell survival was determined by either of two methods:

(a) Trypan blue exclusion assay: Cells were harvested and resuspended in $1 \mathrm{~mL}$ medium, then a $10 \mu \mathrm{L}$ aliquot was mixed with a $10 \mu \mathrm{L} 0.05 \%$ trypan blue solution (Gibco 15250061, Grand Island, NY, USA), placed into a Neubauer chamber, and several fields were observed under a microscope (Olympus CX41). At least 100 cells (in duplicate) were analyzed for viability, and the mean percentage of living cells was calculated [70].

(b) MTT assay was performed according to manufacturer's instructions: In brief, culture media in the plates were substituted with DMEM media without phenol red, and then $500 \mu \mathrm{L}$ of MTT (3-[4,5-dimethylthiazol-2-yl]-2,5-diphenyltetrazolium bromide, Thermo-Fisher Scientific M6494, Waltham, MA, USA) labeling reagent, at a final concentration of $0.5 \mathrm{mg} / \mathrm{mL}$, was added to each well and incubated for $4 \mathrm{~h}$ at $39^{\circ} \mathrm{C}$. The resulting formazan crystals were dissolved using an equal volume of the solubilization solution $(1 \mathrm{~g} / \mathrm{mL}$ SDS in $0.01 \mathrm{~N} \mathrm{HCl})$, and the plates were incubated 
for another $4 \mathrm{~h}$ in a humidified atmosphere at $39^{\circ} \mathrm{C}$. Aliquots $(200 \mu \mathrm{L})$ of soluble formazan product were placed in a 96-well plate and optical density was analyzed at $570 \mathrm{~nm}$ in a microplate reader (Bio-Rad, Mod. 550, Hercules, CA, USA).

\subsection{Determination of Apoptosis by Caspase-3 Activity}

Apoptotic cell death in primary cerebellar cell cultures was analyzed by using a caspase-3 colorimetric assay kit (Assay Designs Inc., Ann Arbor, MI, USA). The samples $(12 \mu \mathrm{g})$ of cell lysates from each treatment, i.e., standards, p-nitroaniline (pNA) standard, and blank controls, were placed in a 96-well plate. After $3 \mathrm{~h}$ of incubation at $37^{\circ} \mathrm{C}$, the reaction was stopped with $1 \mathrm{~N} \mathrm{HCl}$ and then read at $405 \mathrm{~nm}$ in a microplate reader (Bio-Rad, Mod. 550, Hercules, CA, USA). The caspase- 3 enzymatic activity was calculated as units per microgram of protein [71], normalized and expressed as the percentage of activity relative to the normoxic $(\mathrm{Nx})$ controls.

\subsection{Determination of Necrosis by Lactate Dehydrogenase (LDH) Release}

LDH activity was determined following the Vassault method [72]. Briefly, at the end of treatments, $200 \mu \mathrm{L}$ of culture media were mixed with $2.3 \mathrm{~mL}$ of Tris/ $\mathrm{NaCl} / \mathrm{NADH}$ buffer (81.3 mM Tris, $203.3 \mathrm{mM} \mathrm{NaCl}, 0.244 \mathrm{mM} \mathrm{NADH}$, pH 7.2), and $500 \mu \mathrm{L}$ of Tris/ $\mathrm{NaCl} /$ pyruvate (81.3 mM Tris, $203.3 \mathrm{mM} \mathrm{NaCl}, 9.76 \mathrm{mM}$ pyruvate, $\mathrm{pH}$ 7.2) solution; then, the decrease of absorbance at $340 \mathrm{~nm}$, due to the oxidation of $\mathrm{NADH}$, was recorded every minute for $5 \mathrm{~min}$ in a Beckman Coulter-DU 720 UV/Vis scanning a spectrophotometer (Brea, CA, USA). The enzymatic activity was calculated as the relative activity (Units $/ \mathrm{mL}, \mu \mathrm{moles} / \mathrm{min} / \mathrm{mL}$ ), normalized and expressed as percent of the Nx controls.

\subsection{Immunocytochemistry}

For the immunocytochemical analysis (ICC), $5 \times 10^{5}$ cells were plated on a $10-\mathrm{mm}$ culture fluorodish (World Precision Instruments Inc., Sarasota, FL, USA); after treatments, they were fixed with $4 \%$ paraformaldehyde in PBS, pH 7.4, for $30 \mathrm{~min}$. The plates were then washed with PBS and permeabilized with $0.05 \%$ Triton X-100 in PBS. Double staining with specific antibodies (Table 1) and a confocal analysis were performed to study the effects of GH or IGF-1 treatments upon several neuronal cell sub-populations. The occurrence of doublecortin immunoreactivity (DCX-IR) was employed to identify neural precursors, while that of neuronal nuclear protein immunoreactivity (NeuN-IR) for mature neurons. Anti-DCX and anti-NeuN primary antibodies (Table 1) were diluted (1:1000) in TPBS with $1 \%$ nonfat dry milk (Bio-Rad, Hercules, CA, USA), then added to the plates and incubated overnight at room temperature (RT). After washing $(3 \times 15 \mathrm{~min})$ in TPBS, plates were then incubated for $2 \mathrm{~h}$, at RT with the corresponding secondary antibodies: goat anti-rabbit IgGCy3 antibody or rabbit anti-mouse IgG-FITC antibody (at dilutions mentioned in Table 1) in TPBS with $1 \%$ nonfat dry milk (Bio-Rad). Then, plates were washed $(3 \times 15 \mathrm{~min})$ in TPBS and counterstained with $300 \mathrm{nM} 4^{\prime} 6$-diamidino-2-phenylindole (DAPI, Invitrogen) in PBS for $30 \mathrm{~min}$, rinsed three times and stored in TBS. The plates were analyzed using a Carl Zeiss LSM 510 confocal microscope with lasers at excitation wavelengths of $561 \mathrm{~nm}$ (Cy3), and $488 \mathrm{~nm}$ (FITC), respectively. A coherent-XR multiphotonic laser at $350 \mathrm{~nm}$ was also employed for DAPI staining to determine total cell number. 
Table 1. Antibodies.

\begin{tabular}{|c|c|c|c|c|}
\hline Target & Host/Type & Dilution & Source & Cat. No. \\
\hline DCX & $\begin{array}{c}\text { guinea } \\
\text { pig/polyclonal }\end{array}$ & 1:1000 & Sigma-Aldrich & AB2253 \\
\hline NeuN & mouse/monoclonal & 1:1000 & Sigma-Aldrich & MAB377 \\
\hline HIF-1 $\alpha$ & rabbit/polyclonal & 1:1000 & Cell Signaling & $3716 S$ \\
\hline$\beta$-Tubulin III & mouse/monoclonal & $1: 2000$ & Sigma-Aldrich & T8578 \\
\hline $\begin{array}{l}\text { Phospho- } \\
\text { Akt(S437) }\end{array}$ & rabbit/monoclonal & 1:1000 & $\begin{array}{c}\text { Thermo Fisher } \\
\text { Scientific }\end{array}$ & $44-621 G$ \\
\hline $\begin{array}{c}\text { Phospho- } \\
\text { p44/42 MAPK } \\
(\text { Erk1/2) } \\
\text { (Thr202/Tyr204) }\end{array}$ & rabbit/monoclonal & 1:1000 & Cell Signaling & $4370 \mathrm{~S}$ \\
\hline Bcl-2 & rabbit/polyclonal & $1: 1000$ & Invitrogen & 138800 \\
\hline GAPDH & rabbit/monoclonal & $1: 2000$ & $\begin{array}{c}\text { Cell Signaling } \\
\text { Technology }\end{array}$ & $14 \mathrm{C} 10$ \\
\hline $\begin{array}{l}\text { Goat anti-mouse } \\
\text { IgG }(\mathrm{H}+\mathrm{L}) \\
\text { cross-adsorbed } \\
\text { secondary } \\
\text { antibody, HRP }\end{array}$ & goat/polyclonal & 1:5000 & $\begin{array}{c}\text { Thermo Fisher } \\
\text { Scientific }\end{array}$ & G-21040 \\
\hline $\begin{array}{c}\text { Goat anti-rabbit } \\
\text { Ig }(\mathrm{H}+\mathrm{L}) \\
\text { secondary } \\
\text { antibody, HRP }\end{array}$ & goat/polyclonal & $1: 5000$ & Invitrogen & 656120 \\
\hline $\begin{array}{l}\text { Goat anti-guinea } \\
\text { pig IgG antibody, } \\
\text { HRP conjugate }\end{array}$ & goat/polyclonal & $1: 5000$ & Millipore & AP108P \\
\hline $\begin{array}{c}\text { Rabbit } \\
\text { anti-mouse IgG } \\
(\mathrm{H}+\mathrm{L}) \\
\text { secondary } \\
\text { antibody, FITC }\end{array}$ & rabbit/polyclonal & $1: 2000$ & Invitrogen & A16161 \\
\hline $\begin{array}{l}\text { Goat anti-rabbit } \\
\text { IgG antibody, } \\
\text { Cy3 conjugate }\end{array}$ & goat/polyclonal & $1: 5000$ & Millipore & AP132C \\
\hline
\end{tabular}

In an independent set of experiments, the impact of $\mathrm{HI}$ conditions upon cerebellar cells was determined by analyzing the expression of hypoxia-inducible factor 1-alpha immunoreactivity (HIF-1 $\alpha$-IR), as well as the neuronal marker B-Tubulin III, employing the specific antibodies listed in Table 1 . The extent of the cell response to hypoxia-ischemia injury was measured as the ratio of HIF- $1 \alpha-$ IR/DAPI relative area (\%) in the plates.

\subsection{Western Blot Analysis}

Total proteins in primary cerebellar cell cultures were extracted using a homogenization buffer (50 mM HCl-Tris, pH 9.0), complemented with a protease inhibitor cocktail (Mini-complete, Roche, Basel, Switzerland). Equal amounts of protein $(50 \mu \mathrm{g})$ were separated by SDS-PAGE in $12.5 \%$ slabs and transferred onto nitrocellulose membranes (Bio-Rad), as previously described [11]. Nitrocellulose-free binding sites were blocked with $5 \%$ nonfat dry milk (Bio-Rad) in TBS (Gibco, Grand Island, NY, USA) for $1 \mathrm{~h}$, at RT. Membranes were then incubated overnight at $4{ }^{\circ} \mathrm{C}$ with the corresponding specific primary antibodies (Table 1$)$, diluted in TTBS $(0.05 \%$ Tween $[v / v]$ in $1 \times$ TBS). After washing the membranes with TTBS $(3 \times 10 \mathrm{~min})$, they were incubated for $2 \mathrm{~h}$ at RT with the corresponding HRP- 
conjugated secondary antibodies (Table 1). Chemiluminescent immunoreactive bands were developed using the ECL blotting detection reagent on autoradiography film (both from Amersham-Pharmacia, Buckinghamshire, UK). Kaleidoscope molecular weight markers (Bio-Rad, Cat. 1610375) were used as a reference for the molecular mass determination. In order to study the difference between the proportion of phosphorylated vs nonphosphorylated proteins among treatments in the same blots, a stripping method was used [11,71]. The DCX, NeuN, p-Akt, p-ERK1/2, and Bcl-2 immunoreactive bands intensities were normalized to GAPDH band intensity as the protein-loading control. Immunoblots were repeated up to 3 times, scanned, and quantified by densitometric analysis using ImageJ software (developed by NIH, freeware, [73]).

\subsection{RT-PCR}

Total RNA was extracted from each well (3 wells per experimental condition) by adding $1 \mathrm{~mL}$ of Trizol (Invitrogen, Waltham, MA, USA) according to the manufacturer's directions. RNA was purified from cellular lysates using the Zymo Direct-zol purification kit according to instructions (Zymo Research Corp., Irvine, CA, USA). Genomic DNA contamination was removed by DNase I treatment (Invitrogen, Waltham, MA, USA) for $15 \mathrm{~min}$ at RT. The cDNA was synthesized from $1 \mu \mathrm{g}$ of total RNA using $100 \mathrm{U}$ of Superscript III Reverse Transcriptase (Life Technologies, Invitrogen, Waltham, MA, USA), $1 \mathrm{mM}$ dNTPs, $0.5 \mu \mathrm{g}$ oligo $\mathrm{d}(\mathrm{T})$, and $0.5 \mu \mathrm{g}$ random hexamers, for $60 \mathrm{~min}$ at $42{ }^{\circ} \mathrm{C}$.

\subsection{Quantitative PCR ( $q P C R)$}

The expression of GH, GH receptor (GHR), IGF-1, and IGF-1 receptor (IGF-1R) mRNAs was quantified by quantitative PCR (qPCR) in a StepOne Real-Time PCR system (Applied Biosystems, Foster, CA, USA), and using SYBR Green (Roche, Mannheim, Germany) in a $10 \mu \mathrm{L}$ final volume containing $3 \mu \mathrm{L}$ cDNA (diluted 1:3 for GH, GHR, IGF-1, IGF-1R, and 1:5 for $18 \mathrm{~S})$, and $1 \mu \mathrm{L}$ of each specific primer $(0.5 \mu \mathrm{M})$. Primer sets used (Table 2$)$ were designed to amplify avian mRNAs and to cross intro-exon boundaries to control for genomic DNA contamination. Reactions were performed under the following conditions: initial denaturation at $95^{\circ} \mathrm{C}$ for $10 \mathrm{~min}$, followed by 40 cycles at $95^{\circ} \mathrm{C}$ for $15 \mathrm{~s}, 60{ }^{\circ} \mathrm{C}$ for $15 \mathrm{~s}$, and $72{ }^{\circ} \mathrm{C}$ for $20 \mathrm{~s}$. Dissociation curves were included after each qPCR experiment to ensure primer specificity. The relative abundance of GH, GHR, IGF-1, and IGF-1R mRNAs was calculated using the comparative threshold cycle $(\mathrm{Ct})$ method and employing the formula $2^{-\Delta \Delta C T}$ [74], where the quantification is expressed relative to the geometric mean of $18 \mathrm{~S}$ ribosomal mRNA [75].

Table 2. Oligonucleotides.

\begin{tabular}{|c|c|c|c|c|}
\hline Target & Primer & Sequence $\left(5^{\prime}-3^{\prime}\right)$ & Size & Accession Number \\
\hline $\mathrm{cGH}$ & $\begin{array}{l}\text { Fwd } \\
\text { Rev }\end{array}$ & $\begin{array}{l}\text { CGCACCTATATTCCGGAGGAC } \\
\text { GGCAGCTCCATGTCTGACT }\end{array}$ & $128 \mathrm{bp}$ & NM_204359 \\
\hline cGHR & $\begin{array}{l}\text { Fwd } \\
\text { Rev }\end{array}$ & $\begin{array}{l}\text { ACTTCACCATGGACAATGCCTA } \\
\text { GGGGTTTCTGCCATTGAAGCTC }\end{array}$ & $180 \mathrm{bp}$ & NM_001001293.1 \\
\hline cIGF-1 & $\begin{array}{l}\text { Fwd } \\
\text { Rev }\end{array}$ & $\begin{array}{l}\text { TACCTTGGCCTGTGTTTGCT } \\
\text { CCCTTGTGGTGTAAGCGTCT }\end{array}$ & $170 \mathrm{bp}$ & NM_001004384 \\
\hline cIGF-1R & $\begin{array}{l}\text { Fwd } \\
\text { Rev }\end{array}$ & $\begin{array}{l}\text { TCCAACACAACACTGAAGAATC } \\
\text { ACCATATTCCAGCTATTGGAGC }\end{array}$ & $166 \mathrm{bp}$ & NM_205032.1 \\
\hline c18S & $\begin{array}{l}\text { Fwd } \\
\text { Rev }\end{array}$ & $\begin{array}{l}\text { CTCTTTCTCGATTCCGTGGGT } \\
\text { TTAGCATGCCAGAGTCTCGT }\end{array}$ & $100 \mathrm{bp}$ & M59389 \\
\hline
\end{tabular}


CUCUACGGACCGAGG)-3') were custom made (Thermo-Fisher Scientific, Waltham, MA, USA). The transfection protocol employed was previously characterized [76,77] with minor modifications. In brief, siRNA transfections were carried out in a $100 \mu \mathrm{L}$ final volume per dish containing either $70 \mathrm{nM}$ siRNA for GH, or $170 \mathrm{nM}$ for IGF-1, with $2 \mu \mathrm{L}$ of Lipofectamine RNAi MAX (Thermo-Fisher Scientific, Waltham, MA, USA). Lipofectamine and siRNAs were diluted independently in $48 \mu \mathrm{L}$ of Opti-MEM media (Thermo-Fisher Scientific, Waltham, MA, USA) and incubated at RT for $5 \mathrm{~min}$. To produce liposomes, siRNAs and lipofectamine dilutions were mixed during $20 \mathrm{~min}$; then, the cell cultures were exposed to liposomes containing GH or IGF-1 siRNAs, and incubated for $48 \mathrm{~h}$ at $39{ }^{\circ} \mathrm{C}$ in a humidified chamber. Scramble siRNA was used as siRNA control.

\subsection{Statistical Analysis}

In all experiments, values are expressed as mean \pm SEM. Significant differences between multiple groups were determined by one-way ANOVA and Tukey's post hoc test. An unpaired Student's $t$ test was used to compare between two groups where appropriate; $p$ values less than 0.05 were determined to be statistically significant $\left({ }^{*} p<0.05\right.$; ${ }^{* *} p<0.01$; $* * * 0<0.001)$.

Supplementary Materials: The following are available online at https://www.mdpi.com/1422-006 $7 / 22 / 1 / 256 /$ s1.

Author Contributions: Conceptualization, R.B.-L., M.L. and C.A.; methodology R.B.-L., M.C., J.Á.M., S.P.-P., O.V.-M., M.L.; supervision, M.L., J.Á.-M., C.G.M.-M., M.D.-M.; validation: M.L., J.Á.-M., R.B.-L., M.C.; writing—original draft, R.B.-L., M.L., J.Á.-M., C.G.M.-M. and C.A.; writing-review and editing, C.A., C.G.M.-M., M.D.-M., J.Á.-M., M.L. and R.B.-L.; resources and funding, C.A., C.G.M.-M. and M.L. All authors have read and agreed to the published version of the manuscript.

Funding: This work was supported by Programa de Apoyo a Proyectos de Investigación e Innovación Tecnológica de la Dirección General de Asuntos del Personal Académico (PAPIIT-DGAPA-UNAM) (IN207018, IN208419, IN227020), and UNAM grant 1130-202-002 to C.A., Universidad Nacional Autónoma de México (UNAM; México City, México), as well as by Consejo Nacional de Ciencia y Tecnología (CONACYT, México City, México, grant 285004). Scholarships to R.B.-L (MSc and PhD 696979), S.P.-P (PhD, 475619), and postdoctoral fellowship to J.Á.-M (CVU-267642) were provided by CONACYT. R.B.-L was supported by the Alejandro Bayón Fund established by C.A.

Institutional Review Board Statement: The study was conducted according to the guidelines established in "The guide for care and use of laboratory animals", U.S. National Research Council, as well as in the Mexican official regulation (NOM-062-ZOO-1999), and was approved by the bioethical committee of the Instituto de Neurobiología, UNAM (protocol 038, 10/19/2010, ratified on 09/12/2017).

Informed Consent Statement: Not applicable.

Data Availability Statement: The data that support the findings of this study are available from the corresponding author upon reasonable request.

Acknowledgments: The authors thank Pilgrim's Pride, Querétaro, México, who donated the fertilized broiler eggs used during this research. We also thank Gerardo Courtois (lab assistant), Nydia Hernández-Ríos (confocal microscopy) at the INB-UNAM Microscopy Unit, Adriana GonzálezGallardo at the INB-UNAM Proteogenomic Unit, and Ramón Martínez-Olvera at the INB-UNAM Computing Unit.

Conflicts of Interest: The authors declare no conflict of interest.

\section{References}

1. Ajo, R.; Cacicedo, L.; Navarro, C.; Sanchez-Franco, F. Growth hormone action on proliferation and differentiation of cerebral cortical cells from fetal rat. Endocrinology 2003, 144, 1086-1097. [CrossRef] [PubMed]

2. Aberg, D. Role of the growth hormone/insulin-like growth factor 1 axis in neurogenesis. Endocr. Dev. 2010, 17, 63-76. [CrossRef] [PubMed]

3. Frago, L.M.; Pañeda, C.; Dickinson, L.; Hewson, A.K.; Argente, J.; Chowen, J.A. Growth hormone (GH) and GH-releasing peptide6 increase brain insulin-like growth factor-I expression and activate intracellular signaling pathways involved in neuroprotection. Endocrinology 2002, 143, 4113-4122. [CrossRef] [PubMed] 
4. Nyberg, F.; Hallberg, M. Growth hormone and cognitive function. Nat. Rev. Endocrinol. 2013, 9, 357-365. [CrossRef]

5. Devesa, J.; Almengló, C.; Devesa, P. Multiple effects of growth hormone in the body: Is it really the hormone for growth. Clin. Med. Insights Endocrinol. Diabetes 2016, 9, 47-71. [CrossRef]

6. Wasinski, F.; Frazão, R.; Donato, J., Jr. Effects of growth hormone in the central nervous system. Arch. Endocrinol. Metab. 2019, 63, 549-556. [CrossRef]

7. Alba-Betancourt, C.; Arámburo, C.; Ávila-Mendoza, J.; Ahumada-Solórzano, S.M.; Carranza, M.; Rodríguez-Méndez, A.J.; Harvey, S.; Luna, M. Expression, cellular distribution, and heterogeneity of growth hormone in the chicken cerebellum during development. Gen. Comp. Endocrinol. 2011, 170, 528-540. [CrossRef]

8. Arámburo, C.; Alba-Betancourt, C.; Luna, M.; Harvey, S. Expression and function of growth hormone in the nervous system: A brief review. Gen. Comp. Endocrinol. 2014, 203, 35-42. [CrossRef]

9. Devesa, J.; Núñez, I.; Agra, C.; Bejarano, A.; Devesa, P. Treatment with growth hormone (GH) increased the metabolic activity of the brain in an elder patient, not GH-deficient, who suffered mild cognitive alterations and had an ApoE 4/3 genotype. Int. J. Mol. Sci. 2018, 19, 2294. [CrossRef]

10. Isgaard, J.; Aberg, D.; Nilsson, M. Protective and regenerative effects of the GH/IGF-1 axis on the brain. Minerva Endocrinol. 2007, 32, 103-113. [PubMed]

11. Alba-Betancourt, C.; Luna-Acosta, J.L.; Ramírez-Martínez, C.E.; Ávila-González, D.; Granados-Ávalos, E.; Carranza, M.; MartínezCoria, H.; Arámburo, C.; Luna, M. Neuro-protective effects of growth hormone $(\mathrm{GH})$ after hypoxia-ischemia injury in embryonic chicken cerebellum. Gen. Comp. Endocrinol. 2013, 183, 17-31. [CrossRef] [PubMed]

12. Devesa, P.; Reimunde, P.; Gallego, R.; Devesa, J.; Arce, V.M. Growth hormone (GH) treatment may cooperate with locallyproduced GH in increasing the proliferative response of hippocampal progenitors to kainate-induced injury. Brain Inj. 2011, 25, 503-510. [CrossRef]

13. Devesa, P.; Gelabert, M.; González-Mosquera, T.; Gallego, R.; Relova, J.L.; Devesa, J.; Arce, V.M. Growth hormone treatment enhances the functional recovery of sciatic nerves after transection and repair. Muscle Nerve 2012, 45, 385-392. [CrossRef] [PubMed]

14. Devesa, P.; Agasse, F.; Xapelli, S.; Almengló, C.; Devesa, J.; Malva, O.; Arce, V.M. Growth hormone pathways signaling for cell proliferation and survival in hippocampal neural precursors from postnatal mice. BMC Neurosci. 2014, 15, 100. [CrossRef] [PubMed]

15. De Magalhaes Filho, C.D.; Kappeler, L.; Dupont, J.; Solinc, J.; Villapol, S.; Denis, C.; Nosten-Bertrand, M.; Billard, J.-M.; Blaise, A.; Tronche, F.; et al. Deleting IGF-1 receptor from forebrain neurons confers neuroprotection during stroke and upregulates endocrine somatotropin. J. Cereb. Blood Flow Metab. 2017, 37, 396-412. [CrossRef]

16. Martínez-Moreno, C.G.; Calderón-Vallejo, D.; Harvey, S.; Arámburo, C.; Quintanar, J.L. Growth hormone (GH) and gonadotropinreleasing hormone $(\mathrm{GnRH})$ in the central nervous system: A potential neurological combinatory therapy? Int. J. Mol. Sci. 2018, 19, 375. [CrossRef] [PubMed]

17. Martínez-Moreno, C.G.; Fleming, T.; Carranza, M.; Ávila-Mendoza, J.; Luna, M.; Harvey, S.; Arámburo, C. Growth hormone protects against kainate excitotoxicity and induces BDNF and NT3 expression in chicken neuroretinal cells. Exp. Eye Res. 2018, 166, 1-12. [CrossRef] [PubMed]

18. Nylander, E.; Zelleroth, S.; Nyberg, F.; Grönbladh, A.; Hallberg, M. The protective and restorative effects of growth hormone and insulin-like growth factor-1 on methadone-induced toxicity in vitro. Int. J. Mol. Sci. 2018, 19, 3627. [CrossRef]

19. Heredia, M.; Rodríguez, N.; Sánchez Robledo, V.; Criado, J.M.; de la Fuente, A.; Devesa, J.; Devesa, P.; Sánchez Riolobos, A. Factors involved in the functional motor recovery of rats with cortical ablation after GH and rehabilitation treatment: Cortical cell proliferation and nestin and actin expression in the striatum and thalamus. Int. J. Mol. Sci. 2019, 20, 5770. [CrossRef]

20. Aberg, N.D.; Brywe, K.G.; Isgaard, J. Aspects of growth hormone and insulin-like growth factor-I related to neuroprotection, regeneration, and functional plasticity in the adult brain. Sci. World J. 2006, 6, 53-80. [CrossRef]

21. Harvey, S.; Baudet, M.-L.; Sanders, E.J. Growth hormone-induced neuroprotection in the neural retina during chick embryogenesis. Ann. N. Y. Acad. Sci. 2009, 1163, 414-416. [CrossRef] [PubMed]

22. Sanders, E.J.; Parker, E.; Harvey, S. Endogenous growth hormone in human retinal ganglion cells correlates with cell survival. Mol. Vis. 2009, 15, 920-926. [PubMed]

23. Sanders, E.J.; Lin, W.Y.; Parker, E.; Harvey, S. Growth hormone promotes the survival or retinal cells in vivo. Gen. Comp. Endocrinol. 2011, 172, 140-150. [CrossRef] [PubMed]

24. D'Mello, S.R.; Galli, C.; Ciotti, T.; Calissano, P. Induction of apoptosis in cerebellar granule neurons by low potassium: Inhibition of death by insulin-like growth factor I and cAMP. Proc. Natl. Acad. Sci. USA 1993, 90, 10989-10993. [CrossRef]

25. Parrizas, M.; Saltiel, A.R.; Le Roith, D. Insulin-like growth factor 1 inhibits apoptosis using the phosphatidylinositol $3^{\prime}$-kinase and mitogen-activated protein kinase pathways. J. Biol. Chem. 1997, 272, 154-161. [CrossRef]

26. Brywe, K.G.; Mallard, C.; Gustavsson, M.; Hedtjärn, M.; Leverin, A.L.; Wang, X.; Blomgren, K.; Isgaard, J.; Hagberg, H. IGF-I neuroprotection in the immature brain after hypoxia-ischemia, involvement of Akt and GSK3beta? Eur. J. Neurosci. 2005, 21, 1489-1502. [CrossRef]

27. Sanders, E.J.; Lin, W.Y.; Parker, E.; Harvey, S. Growth hormone expression and neuroprotective activity in a quail neural retina cell line. Gen. Comp. Endocrinol. 2010, 165, 111-119. [CrossRef] 
28. Guan, J.; Bennet, L.; Gluckman, P.D.; Gunn, A. Insulin-like growth factor-1 and post-ischemic brain injury. Prog. Neurobiol. 2003, 70, 443-462. [CrossRef]

29. Lee, W.H.; Wang, G.M.; Seaman, L.B.; Vannucci, S.J. Coordinate IGF-I and IGFBP5 gene expression in perinatal rat brain after hypoxia-ischemia. J. Cereb. Blood Flow Metab. 1996, 16, 227-236. [CrossRef]

30. Gluckman, P.; Klempt, N.D.; Guan, J.; Mallard, C.; Sirimanne, E.; Dragunow, M.; Klempt, M.; Singh, K.; Williams, C.; Nikolics, K. A role for IGF-1 in the rescue of CNS neurons following hypoxic-ischemic injury. Biochem. Biophys. Res. Commun. 1992, 182, 593-599. [CrossRef]

31. Le Roith, D.; Bondy, C.; Yakar, S.; Liu, J.L.; Butler, A. The somatomedin hypothesis: 2001. Endocr. Rev. 2001, 22, 53-74. [CrossRef] [PubMed]

32. Stroka, D.M.; Burkhardt, T.; Desbaillets, I.; Wenger, R.H.; Neil, D.A.; Bauer, C.; Gassmann, M.; Candinas, D. HIF-1 is expressed in normoxic tissue and displays an organ-specific regulation under systemic hypoxia. FASEB J. 2001, 15, 2445-2453. [CrossRef] [PubMed]

33. Giusti, S.; Fiszer de Plazas, S. Neuroprotection by hypoxic preconditioning involves upregulation of hypoxia-inducible factor-1 in a prenatal model of acute hypoxia. J. Neurosci. Res. 2012, 90, 468-478. [CrossRef] [PubMed]

34. Ramamoorthy, P.; Shi, H. Ischemia induces different levels of hypoxia inducible factor- $1 \alpha$ protein expression in interneurons and pyramidal neurons. Acta Neuropathol. Commun. 2014, 2, 51. [CrossRef] [PubMed]

35. Jung, S.; Boie, G.; Doerr, H.G.; Trollmann, R. Oxygen-sensitive regulation and neuroprotective effects of growth hormonedependent growth factors during early postnatal development. Am. J. Physiol. Regul. Integr. Comp. Physiol. 2017, 312, R539-R548. [CrossRef]

36. Sharp, F.R.; Bernaudin, M. HIF1 and oxygen sensing in the brain. Nat. Rev. Neurosci. 2004, 5, 437-448. [CrossRef]

37. Liang, X.; Liu, X.; Lu, F.; Zhang, Y.; Jiang, X.; Ferriero, D.M. HIF1 $\alpha$ signaling in the endogenous protective responses after neonatal brain hypoxia-ischemia. Dev. Neurosci. 2019, 1-10. [CrossRef]

38. Fan, X.; Heijnen, C.J.; van der Kooij, M.A.; Groenendaal, F.; van Bel, F. The role and regulation of hypoxia-inducible factor-1alpha expression in brain development and neonatal hypoxic-ischemic brain injury. Brain Res. Rev. 2009, 62, 99-108. [CrossRef]

39. Nisimov, H.; Orenbuch, A.; Pleasure, S.J.; Golan, H.M. Impaired organization of GABAergic neurons following prenatal hypoxia. Neuroscience 2018, 384, 300-313. [CrossRef]

40. Han, T.R.; Chun, M.H.; Jang, D.H.; Kim, K.S.; Lim, K.H.; Cho, H.J. Neuroprotective effects of growth hormone against hypoxicischemic brain injury in neonatal rats: $1 \mathrm{H}$ magnetic resonance spectroscopic study. J. Korean Med. Sci. 2007, 22, 122-126. [CrossRef]

41. Shin, D.H.; Lee, E.; Kim, J.W.; Kwon, B.S.; Jung, M.K.; Jee, Y.H.; Kim, J.; Bae, S.R.; Chang, Y.P. Protective effect of growth hormone on neuronal apoptosis after hypoxia-ischemia in the neonatal rat brain. Neurosci. Lett. 2004, 354, 64-68. [CrossRef] [PubMed]

42. Nylander, E.; Grönbladh, A.; Zelleroth, S.; Diwakarla, S.; Nyberg, F.; Hallberg, M. Growth hormone is protective against acute methadone-induced toxicity by modulating the NMDA receptor complex. Neuroscience 2016, 339, 538-547. [CrossRef] [PubMed]

43. Lai, M.C.; Yang, S.N. Perinatal hypoxic-ischemic encephalopathy. J. Biomed. Biotechnol. 2011. [CrossRef] [PubMed]

44. Van Marle, G.; Antony, J.M.; Silva, C.; Sullivan, A.; Power, C. Aberrant cortical neurogenesis in a pediatric neuroAIDS model: Neurotrophic effects of growth hormone. AIDS 2005, 19, 1781-1791. [CrossRef]

45. Möderscheim, T.A.; Christophidis, L.J.; Williams, C.E.; Scheepens, A. Distinct neuronal growth hormone receptor ligand specificity in the rat brain. Brain Res. 2007, 1137, 29-34. [CrossRef]

46. Christophidis, L.J.; Gorba, T.; Gustavsson, M.; Williams, C.E.; Werther, G.A.; Russo, V.C.; Scheepens, A. Growth hormone receptor immunoreactivity is increased in the subventricular zone of juvenile rat brain after focal ischemia: A potential role for growth hormone in injury-induced neurogenesis. Growth Horm. IGF Res. 2009, 19, 497-506. [CrossRef]

47. McLenachan, S.; Lum, M.G.; Waters, M.J.; Turnley, A.M. Growth hormone promotes proliferation of adult neurosphere cultures. Growth Horm. IGF Res. 2009, 19, 212-218. [CrossRef]

48. Sanchez-Bezanilla, S.; Åberg, N.D.; Crock, P.; Walker, F.R.; Nilsson, M.; Isgaard, J.; Ong, L.K. Growth hormone promotes motor function after experimental stroke and enhances recovery-promoting mechanisms within the peri-infarct area. Int. J. Mol. Sci. 2020, 21, 606. [CrossRef]

49. Lin, S.; Fan, L.W.; Rhodes, P.G.; Cai, Z. Intranasal administration of IGF-1 attenuates hypoxic-ischemic brain injury in neonatal rats. Exp. Neurol. 2009, 217, 361-370. [CrossRef]

50. D'Ercole, A.J.; Ye, P.; Calikoglu, A.S.; Gutiérrez-Ospina, G. The role of the insulin-like growth factors in the central nervous system. Mol. Neurobiol. 1996, 13, 227-255. [CrossRef]

51. D'Ercole, A.J.; Ye, P. Expanding the mind: Insulin-like growth factor I and brain development. Endocrinology 2008, 149, 5958-5962. [CrossRef]

52. Costoya, J.A.; Finidori, J.; Moutoussamy, S.; Seãris, R.; Devesa, J.; Arce, V.M. Activation of growth hormone receptor delivers an antiapoptotic signal: Evidence for a role of Akt in this pathway. Endocrinology 1999, 140, 5937-5943. [CrossRef] [PubMed]

53. Russell, J.W.; Windebank, A.J.; Schenone, A.; Feldman, E.L. Insulin-like growth factor-I prevents apoptosis in neurons after nerve growth factor withdrawal. J. Neurobiol. 1998, 36, 455-467. [CrossRef]

54. Peruzzi, F.; Prisco, M.; Dews, M.; Salomoni, P.; Grassilli, E.; Romano, G.; Calabretta, B.; Baserga, R. Multiple signaling pathways of the insulin-like growth factor 1 receptor in protection from apoptosis. Mol. Cell. Biol. 1999, 19, 7203-7215. [CrossRef] [PubMed] 
55. Zheng, W.H.; Kar, S.; Doré, S.; Quirion, R. Insulin-like growth factor-1 (IGF-1): A neuroprotective trophic factor acting via the Akt kinase pathway. J. Neural Transm. Suppl. 2000, 60, 261-272. [CrossRef]

56. Yang, X.; Wei, A.; Liu, Y.; He, G.; Zhou, Z.; Yu, Z. IGF-1 protects retinal ganglion cells from hypoxia-induced apoptosis by activating the Erk-1/2 and Akt pathways. Mol. Vis. 2013, 19, 1901-1912. [PubMed]

57. Zhao, B.; Zheng, Z. Insulin growth factor 1 protects neural stem cells against apoptosis induced by hypoxia through Akt/Mitogenactivated protein kinase/Extracellular signal-regulated kinase (Akt/MAPK/ERK) pathway in hypoxia-ischemic encephalopathy. Med. Sci. Monit. 2017, 23, 1872-1879. [CrossRef]

58. Wang, X.; Zhu, C.; Qiu, L.; Hagberg, H.; Sandberg, M.; Blomgren, K. Activation of ERK1/2 after neonatal rat cerebral hypoxiaischaemia. J. Neurochem. 2003, 86, 351-362. [CrossRef]

59. Thei, L.; Rocha-Ferreira, E.; Peebles, D.; Raivich, G.; Hristova, M. Extracellular signal-regulated kinase 2 has duality in function between neuronal and astrocyte expression following neonatal hypoxic-ischaemic cerebral injury. J. Physiol. 2018, 596, 6043-6062. [CrossRef]

60. Fleming, T.; Balderas-Márquez, J.E.; Epardo, D.; Ávila-Mendoza, J.; Carranza, M.; Luna, M.; Harvey, S.; Arámburo, C.; MartínezMoreno, C.G. Growth hormone neuroprotection against kainate excitotoxicity in the retina is mediated by Notch/PTEN/Akt signaling. Investig. Ophthalmol. Vis. Sci. 2019, 60, 4532-4547. [CrossRef] [PubMed]

61. Gustafson, K.; Hagberg, H.; Bengtsson, B.A.; Brantsing, C.; Isgaard, J. Possible protective role of growth hormone in hypoxiaischemia in neonatal rats. Pediatr. Res. 1999, 45, 318-323. [CrossRef] [PubMed]

62. Arellanes-Licea, E.C.; Ávila-Mendoza, J.; Ramírez-Martínez, E.C.; Ramos, E.; Uribe-González, N.; Arámburo, C.; Morales, T.; Luna, M. Upregulation of GH, but not IGF1, in the hippocampus of the lactating dam after kainic acid injury. Endocr. Connect. 2018, 7, 258-267. [CrossRef] [PubMed]

63. Devesa, J.; Reimunde, P.; Devesa, P.; Barberá, M.; Arce, V. Growth hormone (GH) and brain trauma. Horm. Behav. 2013, 63, 331-344. [CrossRef] [PubMed]

64. Ong, L.K.; Chow, W.Z.; TeBay, C.; Kluge, M.; Pietrogrande, G.; Zalewska, K.; Crock, P.; Åberg, N.D.; Bivard, A.; Johnson, S.J.; et al. Growth hormone improves cognitive function after experimental stroke. Stroke 2018, 49, 1257-1266. [CrossRef] [PubMed]

65. Vijayakumar, A.; Novosyadlyy, R.; Wu, Y.; Yakar, S.; LeRoith, D. Biological effects of growth hormone on carbohydrate and lipid metabolism. Growth Horm. IGF Res. 2010, 20, 1-7. [CrossRef]

66. Gosney, E.S.; Jara, A.; Basu, A.; Kopchick, J.J. GH in the central nervous system: Lessons from the growth hormone receptor knockout mouse. Open Endocrinol. J. 2012, 6, 34-41. [CrossRef]

67. Donahue, C.P.; Kosik, K.S.; Shors, T.J. Growth hormone is produced within the hippocampus where it responds to age, sex, and stress. Proc. Natl. Acad. Sci. USA 2006, 103, 6031-6036. [CrossRef]

68. Hallberg, M.; Nyberg, F. Growth hormone receptors in the brain and their potential as therapeutic targets in central nervous system disorders. Open Endocrinol. J. 2012, 6, 27-33. [CrossRef]

69. Heredia, M.; Fuente, A.; Criado, J.; Yajeya, J.; Devesa, J.; Riolobos, A.S. Early growth hormone (GH) treatment promotes relevant motor functional improvement after severe frontal cortex lesion in adult rats. Behav. Brain Res. 2013, 247, 48-58. [CrossRef]

70. Tennant, J.R. Evaluation of the trypan blue technique for determination of cell viability. Transplantation 1964, 2, 685-694. [CrossRef]

71. Luna-Acosta, J.L.; Alba-Betancourt, C.; Martínez-Moreno, C.G.; Ramírez, C.; Carranza, M.; Luna, M.; Arámburo, C. Direct antiapoptotic effects of growth hormone are mediated by PI3K/Akt pathway in the chicken bursa of Fabricius. Gen. Comp. Endocrinol. 2015, 224, 148-159. [CrossRef] [PubMed]

72. Vassault, A. (Ed.) Methods of Enzymatic Analysis; Academic Press: New York, NY, USA, 1983; pp. 118-126.

73. Schneider, C.A.; Rasband, W.S.; Eliceiri, K.W. NIH Image to ImageJ: 25 years of image analysis. Nat. Methods 2012, 9, 671-675. [CrossRef] [PubMed]

74. Livak, K.J.; Schmittgen, T.D. Analysis of relative gene expression data using real-time quantitative PCR and the $2^{-\Delta \Delta C T}$ Method. Methods 2001, 25, 402-408. [CrossRef] [PubMed]

75. Vandesompele, J.; De Preter, K.; Pattyn, F.; Poppe, B.; Van Roy, N.; De Paepe, A.; Speleman, F. Accurate normalization of real-time quantitative RT-PCR data by geometric averaging of multiple internal control genes. Genome Biol. 2002, 3. [CrossRef]

76. Baudet, M.L.; Rattray, D.; Martin, B.T.; Harvey, S. Growth hormone promotes axon growth in the developing nervous system. Endocrinology 2009, 150, 2758-2766. [CrossRef]

77. Ahumada-Solórzano, S.M.; Martínez-Moreno, C.G.; Carranza, M.; Ávila-Mendoza, J.; Luna-Acosta, J.L.; Harvey, S.; Luna, M.; Arámburo, C. Autocrine/paracrine proliferative effect of ovarian GH and IGF-I in chicken granulosa cell cultures. Gen. Comp. Endocrinol. 2016, 234, 47-56. [CrossRef] 